NBER WORKING PAPER SERIES

\title{
POLICY EXPERIMENTATION IN CHINA: THE POLITICAL ECONOMY OF POLICY LEARNING
}

\author{
Shaoda Wang \\ David Y. Yang \\ Working Paper 29402 \\ http://www.nber.org/papers/w29402 \\ NATIONAL BUREAU OF ECONOMIC RESEARCH \\ 1050 Massachusetts Avenue \\ Cambridge, MA 02138 \\ October 2021
}

We thank Daron Acemoglu, Isaiah Andrews, Abhijit Banerjee, Tim Besley, Mike Callen, Esther Duflo, Rema Hanna, Max Kasy, Ben Olken, Gerard Padro, Rohini Pande, Gautam Rao, Gerard Roland, Jesse Shapiro, Michael Song, Andrei Shleifer, Jaya Wen, Yang Xie, and Daniel Xu for stimulating comments and suggestions. Weicheng Cai, Qingyu Chen, Andrew Kao, Kaicheng Luo, Jiarui Qian, and Bobing Qiu provided outstanding research assistance. The views expressed herein are those of the authors and do not necessarily reflect the views of the National Bureau of Economic Research.

NBER working papers are circulated for discussion and comment purposes. They have not been peer-reviewed or been subject to the review by the NBER Board of Directors that accompanies official NBER publications.

(C) 2021 by Shaoda Wang and David Y. Yang. All rights reserved. Short sections of text, not to exceed two paragraphs, may be quoted without explicit permission provided that full credit, including $\odot$ notice, is given to the source. 
Policy Experimentation in China: the Political Economy of Policy Learning Shaoda Wang and David Y. Yang

NBER Working Paper No. 29402

October 2021

JEL No. D72,D8,O2,P16,P21

\begin{abstract}
$\underline{\text { ABSTRACT }}$
Many governments have engaged in policy experimentation in various forms to resolve uncertainty and facilitate learning. However, little is understood about the characteristics of policy experimentation, and how the structure of experimentation may affect policy learning and policy outcomes. We aim to describe and understand China's policy experimentation since 1980, among the largest and most systematic in recent history. We collect comprehensive data on policy experimentation conducted in China over the past four decades. We find three main results. First, more than $80 \%$ of the experiments exhibit positive sample selection in terms of a locality's economic development, and much of this can be attributed to misaligned incentives across political hierarchies. Second, local politicians allocate more resources to ensure the experiments' success, and such effort is not replicable when policies roll out to the entire country. Third, the presence of sample selection and strategic effort is not fully accounted for by the central government, thus affecting policy learning and distorting national policies originating from the experimentation. Taken together, these results suggest that while China's bureaucratic and institutional conditions make policy experimentation at such scale possible, the complex political environments can also limit the scope and bias the direction of policy learning.
\end{abstract}

\author{
Shaoda Wang \\ University of Chicago \\ 5757 S University Ave \\ Chicago, IL 60637 \\ shaoda@uchicago.edu \\ David Y. Yang \\ Department of Economics \\ Harvard University \\ Littauer Center M-31 \\ Cambridge, MA 02138 \\ and NBER \\ davidyang@fas.harvard.edu
}

An online appendix is available at http://www.nber.org/data-appendix/w29402 


\section{Introduction}

Determining which policies to implement and how to implement them is an essential government task (e.g., Hayek 1978; North et al. 1990). Policy learning is challenging, as policy effectiveness often hinges on the nature of the policy, its implementation, the degree of tailoring to local conditions, and the efforts and incentives of local politicians to make the policy work.

Many governments have explicitly or implicitly engaged in policy experimentation in various forms in order to resolve policy uncertainty and to facilitate policy learning (e.g., Roland 2000); Mukand and Rodrik 2005). Sophisticated policy experimentation has ranged from sequences of trials and errors to rigorous randomized control trials in subregions of a country. Few, however, can compare to the systematic policy experimentation in China in terms of its breadth, depth, and duration. Since the 1980s, the Chinese government has been systematically trying out different policies across regions and often over multiple waves before deciding whether to roll out the policies to the entire nation.

This project aims to describe and understand China's policy experimentation since the 1980s. Many scholars have argued that the pursuit of extensive, continuous, and institutionalized policy experimentation was a critical mechanism that led to China's economic rise over the past four decades (e.g., Rawski 1995; Cao, Qian, and Weingast 1999; Roland 2000; Qian 2002). Nonetheless, surprisingly little is understood about the characteristics of policy experimentation, or how the structure of experimentation may affect policy learning and policy outcomes.

We focus on two characteristics of policy experimentation that may determine whether it provides informative and accurate signals on general policy effectiveness (Al-Ubaydli, List, and Suskind 2019). First, to the extent that policy effects are often heterogeneous across localities, representative selection of experimentation sites is critical to ensure unbiased learning of the policy's average effects. Second, to the extent that the efforts of the key actors (such as local politicians) can play important roles in shaping policy outcomes, experiments that induce excessive efforts through local political incentives can result in exaggerated signals of policy effectiveness.

We ask three questions. First, has the sample selection in China's policy experiments been representative? Second, do policy experiments create additional incentives and induce extra effort that are not replicable outside of the experimentation? Third, how do the non-representative sample selection and non-representative experimental situation affect government's policy learning and shape national policy outcomes?

To answer these questions, we collect comprehensive data on policy experimentation 
in China between 1980 and 2020. Based on 19,812 government documents, we construct a database of 633 policy experiments initiated by 98 central ministries and commissions. For each policy experiment, we link the central government document that outlines the overall experimentation guidelines with all corresponding local government documents to record its local implementation, and we trace its roll-out across the country. We measure a variety of characteristics of policy experiments based on the associated government documents and other linked datasets, including ex-ante uncertainty about policy effectiveness, career trajectories of central and local politicians involved in the experiment, the bureaucratic structure of the policy-initiating ministries, the degree of differentiation in policy implementation across local governments, and local socioeconomic conditions.

We begin by investigating the selection of experimentation sites. The ability to learn from a balanced, representative sample is a primary goal for the central government, as prescribed by the the National Development and Reform Commission, which oversees many key experiments. Nonetheless, comparing the pre-experimentation characteristics of the locations that are selected as test sites and those that are not, we observe that more than $80 \%$ of the experiments were conducted in sites that are positively selected in terms of local economic conditions. Such deviation from representativeness cannot be fully justified by optimal experimentation considerations. Rather, we document that nearly half of the observed positive selection can be accounted for by misaligned incentives across political hierarchies. Specifically, the level of promotion incentives faced by local politicians (which are greater for politicians who are sufficiently far away from retirement and for those who have ample room for upward mobility) shape their participation in the experiments, and political patronage affects how ministers choose experimentation sites.

Next, we examine whether policy experimentation induces politicians' strategic efforts during experiments, thus generating non-representative experimental situations. Using a triple-differences strategy, we find that during experimentation, local governments spend almost $5 \%$ more funds in the domains relevant to the policy on trial; this is particularly the case for politicians facing stronger promotion incentives. Such an increase in fiscal support is absent when the policy rolls out to the entire country. Moreover, we find that, among local politicians participating in a specific policy experiment, those facing greater career incentives act significantly differently in terms of policy implementation than those politicians who are not facing such strong career incentives. Such differentiation and potential recognition by the central government could earn local politicians substantial political credits.

Finally, we investigate whether the presence of positive selection in experimentation sites and local politicians' strategic efforts during experimentation affect the central gov- 
ernment's policy learning and the national policy outcomes. We present evidence that the central government does not fully account for sample selection and strategic effort when evaluating policy experimentation. Experiments conducted in positively selected sites are substantially more likely to be promoted to national policies. When experimentation sites experienced exogenous positive shocks in fiscal resources (due to unexpected land revenue windfalls during the experimentation) or political incentives (due to local politician turnover occurring during the experimentation), the policies on trial are significantly more likely to be rolled out as national policies despite the fact that the innate effectiveness of these policies is orthogonal to those shocks. Furthermore, we find that evaluations of experimentation outcomes in the presence of positive sample selection and non-representative experimental situation can influence national policy outcomes. When the trial policies are rolled out to the entire country, localities benefit substantially more from the policies if they share similar socioeconomic conditions or comparable local politicians' career incentives with the corresponding experimentation sites. This could systematically bias the effectiveness of reforms in China, and generate distributional consequences across regions.

Taken together, these results highlight that China's remarkable policy experiments, as with any other undertaking in policy learning at this scale, take place in complex political and institutional contexts. On the one hand, certain institutional and bureaucratic conditions may serve as the engine to coordinate experimentation, to motivate politicians' participation, and to stimulate local policy innovations. Experimentation thus can help circumvent political and bureaucratic frictions that may prevent reform and policy adoption. On the other hand, as our results suggest, the very same institutional and bureaucratic contexts also imply the presence of factors that could result in deviation from representativeness in both sample selection and experimental situation. If these characteristics of the policy experiments are not sufficiently accounted for, policy learning can be biased and national policy outcomes may be affected.

This paper brings an important data point to the largely theoretical literature on policy learning and policy experimentation. For example, Aghion et al. (1991) and Callander (2011) provide theoretical frameworks on searching for good policies through experimentation; Dewatripont and Roland (1995) provide justification for the experimentation approach in policy reforms; Qian, Roland, and Xu (2006) study the relationship between government organizational structure and experimentation behavior; Hirsch (2016) analyzes experimentation in political contexts, where the objectives of learning and persuasion across decision-makers are intertwined; and Callander and Harstad (2015) investigate how decentralized jurisdictions strategically engage in policy experimentation, and 
how a central government could help encourage policy convergence. Closest to the context we study, Montinola, Qian, and Weingast (1995), Cao, Qian, and Weingast (1999), Heilmann (2008a, 2008b), and Xie and Xie (2017) study the institutional setup and political logic of China's policy experimentation. We contribute to this body of work by linking the theoretical predictions on when policy experiments should take place and how they should be structured, with the first empirical analyses of the comprehensive set of policy experiments that have been conducted in China over the past four decades. We highlight that specific institutional contexts inevitably affect the structure of experiments and shape their outcomes.

Our work also joins the recent literature on policy learning and policy scale-up. Several studies highlight the structural factors that may limit how policy trials can inform broader outcomes after pilot programs are scaled up (e.g., Davis et al. 2017; Al-Ubaydli, List, and Suskind 2019). The patterns we document - positive experimentation sites selection in general, and, in particular, the diminishing policy effects as the policy is expanded beyond the site of better socioeconomic conditions and extra political incentives - echo the similar findings by Allcott (2015) on the sample selection bias in the Opower energy conservation programs, as well as findings by DellaVigna and Linos (2020) that trials conducted by the Nudge Units had smaller effects when scaled up due to changes in the intervention, institutional contexts, and implementation details. Our finding is also consistent with the prediction by Al-Ubaydli, List, and Suskind 2019 that competition among researchers (in our context, local politicians) could exacerbate the signal biases. Intriguingly, these patterns stand in contrast with the limited positive selection among the US states leading the policy innovations (DellaVigna and Kim 2021) and limited site selection bias in conditional cash transfer and microcredit experiments initiated by the Jameel Poverty Action Lab or Innovations for Poverty Action (Gechter and Meager 2021).

Moreover, as we document that the Chinese government at times fails to disentangle factors not associated with inherent policy effectiveness when evaluating outcomes of policy experimentations, we join a number of recent studies in demonstrating that learning from policy trials may be further affected by decision-makers who are not sophisticated at processing information. They may not internalize information acquisition costs due to political hierarchy (Rogger and Somani 2018), take into account the context

1. Recent work also emphasizes the limits of local policy trials due to the general equilibrium consequences arising from policy scaling up (e.g., Bergquist et al. (2019), and factors related to external validity more generally (Vivalt 2020). Considerations of the external validity of experimental design have been central to much of the discussion, though it is typically focused on individual participants in the policy interventions and experiments, rather than on the localities (e.g., Snowberg and Yariv 2018). 
of the study (Hjort et al. 2019), or consider the uncertainty of statistical inference (Vivalt and Coville 2019). Interestingly, Mehmood, Naseer, and Chen (2021) find that training on causal inference could increase policymakers' demand for and responsiveness to causal evidence on policy effectiveness.

The rest of the paper is organized as follows. Section $\square$ provides institutional background on China's policy experimentation. Section $B$ describes the data sources, the process of constructing the database on policy experimentation, and a number of key characteristics on policy experimentation. Section $₫$ presents results regarding sample selection of experimentation sites. Section 5 presents results on strategic efforts by local politicians during the experiments. Section 6 presents evidence on the consequences of sample selection, strategic efforts and shocks on policy learning and national policy outcomes. Finally, Section $\nabla$ concludes.

\section{Institutional background}

China's policy experimentation represents a process "in which experimenting units try out a variety of methods and processes to find imaginative solutions to predefined tasks or to new challenges that emerge during experimental activity" (Heilmann 2008b).

The central government plays a key role in initiating and coordinating policy experimentation. While China's economic reforms are often accompanied by decentralization, high-powered political centralization remains a key characteristic of China's policy evolution $(\mathrm{Xu}$ 2017). It is thus important to note that China's policy experiments are not freewheeling trial and error or spontaneous policy diffusion. They are "experimentation under hierarchy," specifically, "purposeful and coordinated activity geared to producing novel policy options that are injected into official policy-making and then replicated on a larger scale, or even formally incorporated into national law" (Heilmann 2008b). Such a top-down approach to policy experimentation stands in contrast to the spontaneous experiments that often take place in federalist polities (Shipan and Volden 2006; Cai, Treisman, et al. 2009; Callander and Harstad 2015). While the policy experiments in China often begin with a small set of local governments, if the initiatives are deemed worth pursuing, they quickly move up the political hierarchy and enter a formal experimentation stage (if the central government chooses not to immediately make them national policies).

China's (and the Chinese Communist Party's) tradition of policy experimentation can be traced back to the Communist Revolution during the 1940s, most notably through the sequenced implementation of land reform in selected regions in order to consolidate the Communist regime. Interestingly, such policy experiments were driven primarily by the 
lack of state capacity - policies as complicated as the land reform simply could not be implemented simultaneously and in a uniform manner across all regions under the Communist rule. The Communist Party took advantage of this policy implementation process, continuously adapting and tailoring policies as they were rolled out across localities. This became the earliest form of the "from points to surface" characteristic that defines China's policy experimentation.

Conducting policy experimentation before adopting the policies nationwide was institutionalized by Deng Xiaoping and Chen Yun in the 1980s and 1990s as a core principle guiding the reform and opening-up era policy transitions (Heilmann 2008a; Xie and Xie 2017). While the policy experiments during the Communist Revolution and early years of the People's Republic of China typically involved pre-conceived, centrally-imposed model emulation, the policy experiments during the Reform and Opening-up era are distinguished by their open-endedness in generating novel policy instruments and policy solutions. The "institutional entrepreneurship" released by policy experimentation has long been regarded as a key factor ensuring the stable deepening of China's economic reforms (Naughton 1996).

Primary form of experimentation: experimentation points The most pervasive form of policy experimentation in China is the selection of "experimentation points" (Shidian), as noted by Heilmann (2008a, 2008b). Before deciding whether a new policy should be implemented nationwide, the central government first tries out the policy regionally in a limited number of sites, possibly repeating the experiment in several waves, in order to evaluate the costs and benefits of the policy. Such a gradual approach allows effective policy innovations to precede "from point to surface," which could help avoid costly mistakes at the national level.

Heilmann 2008b describes China's policy experiments in general, and experimentation points in particular, as an inherently political process:

[T]he effectiveness of experimentation is not based on all-out decentralization and spontaneous diffusion of policy innovations. China's experiment-based policy making requires the authority of a central leadership that encourages and protects broad-based local initiative and filters out generalizable lessons but at the same time contains the centrifugal forces that necessarily come up with this type of policy process.

The central government generally announces and introduces the policy experiments by publishing general guidelines. Such documents are issued by the ministries and commissions that lead the experiments, sometimes co-signed by coordinating ministries or 
the State Council if inter-ministerial coordination is involved. The local government of each experimentation site typically responds to the central government documents by publishing a local experimentation action plan, laying out logistical and implementation details for the experiment.

The central government usually directly assigns certain regions as sites for experiments, but sometimes solicits local governments that would be willing to participate (Zhou 2013). Typically, the central government chooses experimentation sites at the province level, and then the provincial governments further delegate the experimentation to specific prefectural cities or counties within their jurisdictions.

A subset of the policy experiments is clustered in "experimental zones" (Shiyanqu). These are regions selected by the central government and given broad discretionary powers to try out various new policy bundles, essentially "creating a new system alongside, or in the interstices of, the existing one" (Naughton 1996). ${ }^{\text {[. }}$

Once a policy experiment is determined to be successful, certain experimentation points are set as "demonstrational zones (Shifanqu)," and their experience in implementing the new policy will be actively promoted by the central government to the rest of the country (hence the term, "from point to surface"). Effective policies based on the experiments eventually are formalized by the central government and become national policies. In contrast, if a policy experiment fails to generate desirable outcomes - whether due to the policy's inherent ineffectiveness, local political economy constraints, high implementation cost, or unexpected public pressure against its implementation - the policy experimentation quietly stops expanding beyond the initial implementation stage. Few failed policy experiments are explicitly canceled.

In this paper, we focus primarily on policy experiments through experimentation points, including those clustered in experimentation zones. Most major reform initiatives in post-Mao China have been tried out by means of experimentation points before they were rolled out to the entire country (if at all); Appendix A.1 describes several other, less common forms of policy experimentation in China. Notable examples of policy experimentation through experimentation points in recent decades include reforms in local fiscal empowerment (2002 - 2015), carbon emission trading (2011 - 2021), separation of permits and licenses (2015 - 2018), and introduction of agriculture catastrophe insurance (2017 - 2021). We will describe these experiments in greater detail in Section 3.3.

2. The purpose of the experimental zones is to explore integrated bundles of economic development policies, rather than to evaluate the effectiveness of a specific policy, which is conceptually closer to Sachs (2006). The most notable examples for experimental zones are the Shenzhen Special Economic Zone and Shanghai Pudong Special Economic Zone, which have served as policy laboratories for various reforms during the Reform-and-Opening era. 


\section{Data and characteristics of policy experimentations}

We compile, to the best of our knowledge, the most comprehensive dataset on policy experimentation in China over the past four decades. Our primary data source relies on official government documents, which we describe in Section 3.1. We also complement the government documents with a number of auxiliary datasets such as local socioeconomic conditions and the background of involved politicians; we describe these data sources in Appendix B. We present, in Section 3.2, a number of characteristics of the policy experiments that we construct based on the government documents and auxiliary datasets. We illustrate four policy experiments as stylized examples in Section B.3.

\subsection{Government documents on policy experimentation}

Our main data is based on the comprehensive collection of policy documents issued by the Chinese central and local governments since 1949 compiled by PKULaw.com, an online platform hosted by Peking University Law School.

Specifically, we collect (nearly) the universe of government documents between 1980 and 2020 containing the key words "experimentation points" (Shidian) and "experimental zones" (Shiyanqu). We obtain 19,812 documents in total, among which 4,399 were issued by the central government and 15,413 by local governments. Central government documents mark the official initiation of particular policy experiments, their key milestones (e.g., when a major expansion of experimentation is planned), and decisions to roll out the policies to the entire country if the experiment is successful. Local government documents are issued by each locality participating in the experiments, specifying details on local implementations and administrative arrangements.

We identify 633 distinct policy experiments based on policy themes. Our categorization of policy experiments is conservative: consecutive experiments are grouped into the same policy experiment as long as they concern similar policy aims, even if the specific contents of the policies evolve and even if the names of the policies change. Moreover, policy experiments that are closely related and simultaneous in implementation are combined into one experiment, even if the central government issued separate documents for each component. ${ }^{\text {[] }}$ We distinguish different phases of the experiments by distinct waves of the experimentation roll-out, often marked by specific central government documents.

3. For example, experiments on corn seed insurance, rice production insurance, professional farmer training, and agricultural tech promotion consulting service are combined into an overarching experiment on improving agricultural technology and management. 
Among the 633 policy experiments, 594 involve policies explicitly intended for potential national roll-out, and 39 are policies with specific regional targets. ${ }^{-1}$ For the baseline analysis in Section 14 where we examine experimentation sites selection, we exclude policies with explicit regional targets, though the results are robust if we include all policy experiments in the analyses and adjust the corresponding comparison of experimentation sites selection based on scope. Around 104 of the policy experiments are ongoing, and we will exclude them from the analyses in Section 6 where we examine whether the policies on trial roll out to the entire country.

Coverage of policy experimentation Initiation of experimentation from inside the government is by far the most frequent starting point (Heilmann 2008b). Government-initiated experiments have corresponding government documents, ensuring our comprehensive coverage on such experiments. In particular, our data includes extensive coverage on potentially failed experiments, as well as government documents that are expired, void, or explicitly revoked.

We conduct various cross-checks to ensure the comprehensiveness of the government documents that we collect. Specifically, for the ministries that publish documents on their own websites, we independently collect documents from the ministerial websites. We find that the government documents collected from the PKULaw.com has extensive and comprehensive coverage (see Appendix Table A.1). When we manually examine the limited documents that are published on the ministries' websites but not included in the PKULaw.com database, we find that they are secondary documents and do not contain information on policy experiments.

Because we are relying on government documents to describe policy experiments, the experiments must have reached a stage of formal endorsement and coordination by the central government in order to be included in our sample. ${ }^{\text {. }}$ Thus, we do not observe very early stage experiments initiated by the local governments that never reach the level of the central government - e.g., early bottom-up policy entrepreneurship led by specific local governments that fail to receive the central government's approval for continuing and expanding the policy. This implies that the set of centrally coordinated policy experiments that we study is already positively selected in terms of the central government's prior evaluation of the policy's effectiveness. However, such sample selection does not

4. Examples of regional target policies are: anti-poverty policies aimed at rural regions, Chinese language education policy aimed at regions with a high share of ethnic minority population, industrial restructuring policy for the Northeast region, and free trade zone trials targeted at a few major ports such as Shanghai.

5. Promising policy innovations initiated by the local government escalate to the central government fairly rapidly, typically within a year or two after the first instance of the local policy trials. 
mean that policy uncertainty is irrelevant in this context: on average, $46 \%$ of the policy experiments fail to become national policies, even though the central government envisioned all of them as having relatively high promise at the onset.

\subsection{Characteristics of policy experiments}

We extract several key pieces of information from the corresponding government documents in order to characterize each policy experiment.

Time of initiation We first extract information on the year when policy experiments are initiated. Figure $\square$ plots the number of experiments initiated in each year across the past four decades, where we record the first year when a specific policy experiment started as the year associated with the multi-year roll-out of the experimentation. We observe a hump-shaped pattern: the number of policy experiments initiated by the central government remained relatively low throughout the decades of the 1980s and 1990s, averaging less than 10 new experiments per year across all ministries and commissions. The number of experiments began to sharply increase toward the end of the 1990s, reaching a peak of 76 new experiments initiated in 2013 alone. Since 2013, the number of new experiments started to decline, and nearly halved by the end of our sample period in 2020.

While many factors could contribute to these patterns, at least part of the decline in the number of experiments in the recent decade can be attributed to the vertical management transition of many state ministries. As these ministries shift the control over their personnel, funding, and decision rights from the local governments to the upperlevel ministerial units, they move away from flat, multi-divisional structures (M-form) that may provide flexibility and ease in coordinating policy experiments, to more centralized, unitary structures (U-form) that benefit from economies of scale. Consistent with the theoretical predictions (e.g., Chandler 1962; Williamson 1975; Qian, Roland, and $\mathrm{Xu}$ 2006), we find that, following the transition to U-form organization, the vertically managed ministries significantly decreased the number of policy experiments that they administer. Appendix $C$ presents results using an event study design.

Experimentation sites and the roll-out schedule We extract the experimentation sites and the roll-out schedule of each policy experiment. Many policy experiments have more than one wave of roll-out, and we identify 1,374 distinct rounds of roll-out across the 633 experiments. We link each government document to a specific round of experimentation, which allows us to observe the time localities join a particular policy experiment and to compare the selection pattern of experimentation sites across rounds. 
Figure प, Panel A plots the distribution of experimentation sites across China, aggregated at the province level (see Appendix Figure A.1 for county level distribution). Table M, Panel A presents the total number of policy experiments initiated during 1980 and 2020 and the average number of rounds and experimentation sites involved in each experimentation. On average, each policy experiment initiated by the central government contains more than two rounds in its roll-out and lasts for 2.25 years, until either the roll-out stops or the experiment becomes a national policy.

Policy domains and involved ministries We identify all the central government ministries and commissions involved in a policy experiment, and measure each ministry or commission's role in that experiment (e.g., initiator or collaborator). In cases where a particular policy experiment is introduced by multiple ministries and commissions, we also identify the primary ministry or commission that takes the leading role. A total of 98 ministries and commissions are involved, ranging from the State Council to the Ministry of Agriculture and the Ministry of Finance. Table M, Panel B presents the number of policy experiments initiated by different ministries and commissions, grouped by policy domains and broad functions for which they are responsible. Appendix Figure A.2 plots the count of policy experiments by policy domain over time.

National roll-out We observe whether policy experiments are rolled out to the entire country and become national policies. This is marked by specific central government documents concluding the experimentation cycle. Overall, $53.9 \%$ of the policy experiments eventually became national policies, while $46.1 \%$ failed (see Figure $\mathbf{2}$, share of successful and failed experiments indicated by darker and lighter gray shades, respectively). The share of policy experimentation leading to national policy roll-out remains remarkably stable over time (see Appendix Figure A.3). The patterns concerning successful and failed policies are not sensitive to the particular definition; for example, we alternatively define a policy experiment as successful if the roll-out covers at least two-thirds of the whole country's counties, and we find similar patterns throughout (see Appendix Figure A.4).

Importance, complexity, and uncertainty We measure the importance, complexity, and ex-ante uncertainty of each policy experiment. We capture the degree of importance by whether an experiment is explicitly mentioned in the central government's Five Year Plans, which represent the most important policy blueprints issued by the Chinese government and cover policy agendas considered as of highest priority in the upcoming five-year period. $19.2 \%$ of the policy experiments reflect policy themes mentioned in the Five Year 
Plans (see Appendix Figure A.5). We capture the degree of complexity by the number of ministries and commissions involved in the experiment, as well as the length of the initial documents describing the experiment. $24.3 \%$ of the policy experiments involve more than two ministries and commissions; we label these as complex experiments (see Appendix Figure A.6). We capture the degree of ex-ante uncertainty of policy experimentation based on whether the central government has laid out a detailed national roll-out timeline before the experiment starts. $30.7 \%$ of the experiments feature such timelines (which we label as experiments on policies with high certainty), and $62.0 \%$ of them eventually become national policies. In contrast, among the $69.3 \%$ of experiments that do not feature such a timeline (which we label as experiments on policies with high uncertainty), only $36.2 \%$ were eventually rolled out to the entire country (see Appendix Figure A.7).

Assigned vs. voluntary participation We categorize policy experiments as either assigned or voluntary, depending on whether the experimentation sites are designated and assigned by the central government directly, or the experiment invites voluntary participation of the local governments. About $40.0 \%$ of the experiments allow (at least partially) for voluntary participation of the local governments (see Appendix Figure A.8).

Auxiliary characteristics Finally, we measure a number of auxiliary characteristics of policy experiments, which we incorporate into various parts of the analyses. For example, we identify whether the central government would provide additional fiscal support for the experimentation sites, and whether the policies on trial would in principle benefit from extra fiscal support. These characteristics will help us evaluate the plausibly strategic fiscal resources allocated by the local governments in order to improve the local outcomes of the experiments. We also measure how policy innovation and differentiation evolve across time and space, by constructing matrices of pairwise textual similarities for all the local policy documents that belong to the same policy experiment. ${ }^{\text {I }}$ Such measurement allows us to investigate the conditions under which local governments exert greater efforts to differentiate their local policy implementation.

\subsection{Four examples of policy experimentation}

We map four distinct policy experiments to illustrate the ranges of policy experimentation that took place in recent decades (see Appendix A.2 for additional details).

6. Text similarity is calculated using Latent Similarity Analysis, a canonical choice in natural language processing. After removing stop words, we conduct the TF-IDF encoding for each word vector, and then use the first three principal components to compute cosine similarity. 
Figure I, Panel B.1 depicts the experimentation on carbon emission trading policy initiated in 2011, which involves five prefectures (Beijing, Tianjin, Shanghai, Shenzhen, and Chongqing) and two provinces (Guangdong and Hubei), all of which are among the most developed localities in the country. The policy rolled out to the entire country in 2021, after just one wave of experimentation. Panel B.2 depicts the experimentation on a policy that aims at reducing administrative burdens to firm entry by separating permits from licenses for new firms: since 2015, the experiment has taken place among 24 prefectures over three waves, very much concentrated in the developed, coastal regions and provincial capitals. This policy rolled out to the entire country in 2018.

Panels B.3 and B.4 describe two experiments that did not lead to national policies. The experimentation on the introduction of agriculture catastrophe insurance started in 2017, and a total of 14 provinces participated as experimentation sites over two waves (see Panel B.3). These experimentation sites are inland provinces in Eastern China, as well as those in the Northeast. The experimentation ended after two waves and this policy did not roll out to the entire country. Finally, as depicted in Panel B.4, the experimentation on county fiscal empowerment reform took place over more than a decade, involving 1,246 counties as experimentation sites across more than 10 waves. The experimentation started with developed regions in the earlier waves and moved towards inland, less developed regions. The experimentation ended in 2015 and the fiscal empowerment reform did not roll out to the country.

\section{Is the selection of experimentation sites representative?}

Focusing on the policy experiments that are meant to test potential national policies, we first examine which localities are selected as experimentation sites. As a benchmark, we examine whether the selection of experimentation sites is indeed representative.

From the central government's perspective, a key criterion for experimentation site selection is its representativeness, which determines the quality of knowledge one could extract from a policy experiment (Zhou 2013). The National Development and Reform Commission, the leading governance body that guides and coordinates national policies, lays out the overall principles of choosing experimentation sites as:

The balanced distribution of experimentation sites is the most important criteria in choosing these sites. [...] Policy experiments are not meant to solve development problems of a particular place or a particular sector. Rather, they need to gather knowledge and experiences for the policy reform and institu- 
tional innovation at the national level. [...] Hence, the experimentation sites should be fairly representative.

\subsection{Procedure to test for representativeness}

For each policy experiment, we compare pre-experimentation characteristics between locations where the experiment is implemented and those that do not participate in the experiment. As the baseline, we examine the local GDP per capita in the year prior to experimentation roll-out.

We conduct t-tests against the null hypothesis that the pre-experimentation levels of local GDP per capita are indistinguishable among the experimentation sites and nonexperimentation sites. This amounts to 633 independent $t$-tests, one for each policy experimentation. ${ }^{\square}$ Note that conducting representativeness tests separately for each policy experiment is conservative: if one were to identify deviations from representativeness with these separate tests, then a pooled test with multiple experiments would yield more power in detecting unrepresentativeness and rejecting the null hypothesis. We discuss below the robustness of using a variety of other local characteristics as well as alternative testing methods.

We use the corresponding t-statistics as summary statistics to quantify the deviation from representativeness for each policy experiment. Specifically, the studentized-t statistic for policy experiment $i$ is:

$$
t_{i}=\frac{\hat{Y}_{i}(1)-\hat{Y}_{i}(0)}{\sqrt{\frac{\hat{S}_{i}^{2}(1)}{n_{i, 1}}+\frac{\hat{S}_{i}^{2}(0)}{n_{i, 0}}}},
$$

following the t-distribution with degrees of freedom $v_{i}$, where

$$
v_{i}=\frac{\left(\frac{s_{i, 1}^{2}}{n_{i, 1}}+\frac{s_{i, 2}^{2}}{n_{i, 2}}\right)^{2}}{\frac{\left(s_{i, 1}^{2} / n_{i, 1}\right)^{2}}{n_{i, 1}-1}+\frac{\left(s_{i, 2}^{2} / n_{i, 2}\right)^{2}}{n_{i, 2}-1}} .
$$

The specific context of China's policy experimentation poses two important complications in conducting the representativeness tests. First, policy experiments can be implemented at the provincial level, prefectural level, or county level. ${ }^{\mathbb{8}}$ The county and pre-

7. For each policy experiment's representativeness test, we adjust the respective degree of freedom in the underlying distribution based on the exact share of localities that participate in the experiment.

8. Centrally-administered municipalities are considered as either provinces or prefectures, depending on the level of policy experimentation implementation. As we discuss below, our baseline patterns remain robust if we exclude these municipalities from the analyses. 
fectural level experimentations often represent cases where experimentation provinces are selected by the central government, and the corresponding provincial governments then choose the counties or prefectures within their jurisdictions to implement the experiment. Thus, the experimentation sites selection has distinct administrative samples. We conduct the representativeness tests at the appropriate level for each policy experiment. For county and prefectural level experiments, the tests are conducted at the corresponding county or prefectural level, stratified based on the experiment-participating provinces - in other words, counties or prefectures participating in the experiment are compared only with other non-experimenting counties or prefectures within the same province.

Second, approximately one-fourth of the experiments involve only one experimentation site. We cannot conduct standard statistical tests for these one-site experiments. Instead, we pool each one-site experiment with four other randomly selected one-site experiments, and conduct the representativeness test on the pooled sample, where the non-experimentation sites are defined as those that do not participate in any of the five experiments. This will yield a corresponding t-statistic for each of the one-site experiments. We conduct a range of alternative test specifications concerning these one-site experiments, such as pooling experiments that take place in consecutive periods, and drawing bootstrap samples with replacement.

\subsection{Most experimentation sites are positively selected}

We plot, in Figure B, Panel A, the distribution of the t-statistics on comparing pre-experimentation local GDP per capita between the experimentation and non-experimentation sites. We mark the thresholds of $t$-statistics where one would reject the null hypothesis of represen-

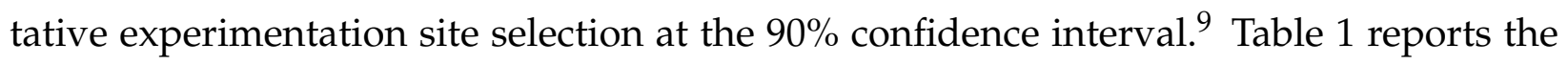
corresponding test statistics (adjusting for the degree of freedom for each test) and the share of policy experiments for which we can reject the null hypotheses at the $10 \%$ level.

We find that the experimentation sites for $80.7 \%$ of the experiments are richer on average (in terms of pre-experimentation local GDP per capita) than localities that do not participate in the corresponding experiment. Even with statistical tests that are fairly conservative, we are able to reject the null hypothesis of representative selection among $50.5 \%$ of the experiments at the $10 \%$ level.

9. As discussed above, each of the $633 t$-tests has its specific degree of freedom. We depict visually the average width of the $90 \%$ confidence interval (2.36).

10. We observe modest decrease in the positive selection of experimentation sites over the years, suggesting potential learning and adjusting by the central government. Appendix Figure A.9 plots the overall share of positively selected experiments over the four decades since 1980, and Appendix Table A.2 presents regression results on the time trend in experimentation's positive selection, for all experiments and separately 
The pattern of positive selection of experimentation sites is remarkably robust. First, we observe similar patterns of positive selection when conducting tests using alternative regional pre-experimentation characteristics such as total local GDP, local population size, and local fiscal revenue (Figure B, Panel B presents the summary statistics; see also Appendix Figure A.10, Panels A to C, respectively). Second, even stronger positive selection is observed when we zoom in to particular policy domains. For example, agricultural policy experiments take place in localities with substantially higher pre-experimentation agricultural output; experiments with government finance and tax policies take place in localities with substantially higher local fiscal revenue; and experiments with population and health policies take place in localities with substantially larger population (see Appendix Figure A.11). ${ }^{\square}$ Pooling all policies together and focusing on pre-experimentation fiscal expenditure in the policy-specific expenditure categories, we again find strong patterns of positive selection (see Appendix Figure A.10, Panel D). Third, the patterns are similar when we incorporate one-site experiments: the representative tests pooling consecutive experiments display similar patterns (see Appendix Figure A.13, Panel A). It is robust to a variety of ways in which we pool and specify random draws of the pooled tests among the one-site experiments (see Appendix Figure A.13, Panel B), and to alternative permutation tests among the multi-site experiments (see Appendix Figure A.13, Panel C). Fourth, the pattern of positive selection is robust if we examine just the subsample of early-round experimentation sites, effectively holding fixed the number of experimentation sites across policy experiments (see Appendix Figure A.14). Finally, the pattern of positive selection is robust if we exclude the selection of centrally-administered municipalities such as Beijing and Shanghai, where local economic development and central government's priority in policy implementation coincide (see Appendix Figure A.15).

\subsection{Unlikely explanations of the observed positive selection}

What may explain the positive selection of experimentation sites? We next document a number of stylized patterns that could help rule out certain explanations.

Ex-ante policy uncertainty One may speculate that, depending on the ex-ante uncertainty that the central government holds toward each policy on trial, the specific objectives of the experimentation could differ and thus justify the deviation from representa-

by ministry.

11. Taking into account of the fact that different policy domains have different unit of analyses - for example, estimating policy effects on firms may require positive selection on counties as experimentation sites - does not explain vast majority of the positive selected policy experiments that we observe (see Appendix Figure A.12). 
tive sample selection. Experiments on policies that the central government is more certain about rolling out to the entire country (captured by whether the central government specifies a timeline for such national roll-out before the experiment starts) might not have learning about policy effectiveness as the primary goal. However, when we separately evaluate the degree of representativeness in site selection among experiments that are exante certain and those that are ex-ante uncertain (see Table W, Panel D), we find that the site selection bias among ex-ante uncertain policies is in fact substantially higher (average $\mathrm{t}$-statistics $=2.95$ ) than that among ex-ante certain policies (average t-statistics $=2.12$ ).

Complex experiments Positive selection of experimentation sites could be justified if richer localities - often represented by better local governance and administrative capacity - may be better at carrying out the demanding trial policies and thus provide more precise signals on the policy effectiveness. Such justification for positive selection could be even stronger for complex experiments, for example, those that involve coordination and collaboration across multiple ministries and local government bodies. Nonetheless, as shown in Table $\mathbb{U}$, Panel E, we observe that the site selection among experiments that are less complex, involving a single ministry or commission, deviates (slightly) further from representative than those that are more complex, multi-ministerial experiments (average t-statistics $=2.84$ vs. 2.65 , respectively).

Eventual scope of policy roll-out Positive selection of experimentation sites could also be justified if the intended geographic scope of the eventual policy is limited to richer localities. While the vast majority of the policy experiments initiated by the central government concerns national policies, there exist different degrees of flexibility in regional

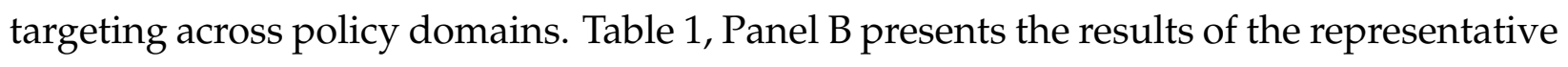
tests for experimentation across policy domains. We observe that experiments on policy domains such as market supervision that are more likely to be nationally uniform are more positively selected (average t-statistics $=3.22$ ) than domains such as agriculture that are more flexible in terms of sub-national targeting (average $\mathrm{t}$-statistics $=1.98$ ).

Optimal experimentation Unrepresentative roll-out of experimentation may be justified if the central government has other objectives in addition to learning about the true underlying treatment effects and persuading other agents who might hold different priors. To evaluate the importance of these alternative objectives, we conduct quantitative exercises to incorporate alternate objectives studied by the recent literature. Specifically, we examine the incentives of subjective expected utility, in addition to learning and per- 
suasion, following Banerjee et al. 2020. We simulate the optimal experimentation design, parameterizing the model based on data from the 25th, 50th, and 75th percentile Chinese policy experiments in terms of their degree of positive selection. Appendix D.1 provides details on the simulation procedure.

We find that when the central government places heavier weight on its subjective expected utility, deterministic experimentation becomes more justified than randomization. However, even if one places $100 \%$ of the weight on the decision maker's subjective expected utility, only less than $5 \%$ of the optimal designs for these experiments induce positive selection with $t$-stats $>1$, with the optimal $t$-stat never exceeding 2.6 - substantially lower than the positive selection that actually occurs.

We additionally test two extensions on the model presented: (i) allow for the experimental information (or equivalently, policy execution) quality to vary with local county's GDP; and (ii) allow counties to consent or opt-in to treatment so that only counties with positive treatment effects are treated. Although both extensions mildly increase selection, the $t$-stats from these simulations still remain much lower than those observed in reality.

\subsection{Political sources of deviation from representative sample selection}

Could positive selection occur even if the central government genuinely intends to conduct representative experimentation, as suggested by the National Development and Reform Commission? Does the central government have alternative goals or constraints that prevents it from executing representative sample selection? In this section, we investigate the political factors that lead to the sample selection.

Local politicians' career incentives We first examine how the prefectural leaders' incentives for career advancement affect their participation in policy experimentation.

A number of patterns suggest that local politicians' incentives to positively represent the results of policy experiments indeed play a role in generating positive site selection. First, on average, participation in successful policy experiments is associated with a $22.3 \%$ increase in promotion probability for the corresponding local politicians (see Appendix Table A.3). When local politicians are facing stronger career incentives in a certain year, they may have stronger motives to improve their portfolio of political achievements, including through participation in important and successful policy experiments ( $\mathrm{Wu}$ 1995; Huang $200(0)$. Second, we find that the deviation from representativeness is not nearly as severe at the province level, as compared to the choices of specific prefectures and counties to be the experimentation sites (see Table $\mathbb{\mathbb { U }}$, Panel C). Third, experiments are closer to being representative if the site selection is assigned by the central government directly 
rather than involving voluntary participation by the local government (see Table $\mathbb{U}$, Panel F).

To test this hypothesis more formally, we follow Wang, Zhang, and Zhou (2020) and estimate each prefectural city leader's ex-ante likelihood of promotion in each year, as a flexible function of their age (relative to retirement), tenure and official rank in the bureaucratic system (capturing the potential for upward mobility); Appendix B.1 provides details of the construction of this measure.

Then, we estimate the following econometric model by exploiting within-prefecture changes in leaders' political incentives:

$$
y_{p t}=\alpha \cdot \text { Incentive }_{p t}+X_{p t}^{\prime} \cdot \beta+\delta_{p}+\theta_{t}+\varepsilon_{p t},
$$

where $y_{p t}$ is the number of policy experiments in prefectural city $p$ in year $t$; Incentive $p t$ is the estimated promotion incentive index for the political leader of region $p$ in year $t$; and $X_{p t}^{\prime}$ is a vector of time-variant regional control variables. Importantly, we control for full sets of region fixed effects and year fixed effects ( $\delta_{p}$ and $\theta_{t}$, respectively), thus identifying the political incentive effects from within-prefecture, across-year discontinuous changes in career incentives, due either to politicians' aging and changes in their opportunities for promotion or to local leaders' routine turnover.

As shown in Table Z, Panel B, when the prefectural leaders have stronger promotion incentives, the corresponding localities engage in significantly more policy experiments. Reassuringly, we do not observe similar effects with the promotion incentives among the preceding politicians who should not have direct influence on subsequent engagement in policy experiments (see Appendix Table A.4). Moreover, such effects of promotion incentives are almost entirely driven by policy experiments initiated by $\mathrm{M}$-form ministries (see in Appendix Table A.5). Since the U-form ministries are directly administered by the central government, the local politicians would have neither capacity nor incentives to influence experiments initiated by U-form ministries (as compared to those initiated by $\mathrm{M}$-form ministries). This is because U-form initiatives are not under the jurisdiction of local governments, and, as a result, local politicians receive less credit for successful experimentation. This pattern also suggests that our findings are unlikely driven by omitted confounding factors: an omitted factor could confound our results only if it were correlated specifically with policy experiments initiated by M-form ministries.

Political patronage Misaligned incentives could also be present within the central government - between the policy experimentation coordination bodies such as the National Development and Reform Commission and the specific ministries in charge of the experi- 
mentation. Given the potential political rewards associated with successful policy experimentation, political patronage - prevalent in China's political system (Fisman and Wang 2015; Fisman et al. 2020) - could also shape the selection of experimentation sites, due to reasons such as favor exchange, higher trust among political patriots, and ministers' better control over local implementation.

To investigate this hypothesis, we exploit the inter-temporal changes in a region's connection to each ministry caused by the turnover of ministers at the central government level. Specifically, we define a province as connected to a ministry if the current minister used to work full-time in that province before becoming the minister. To the extent that the local governments cannot influence the appointment of central ministers, the turnover of ministers can be regarded as exogenous shocks to the province-ministry connections.

We estimate the following econometric model using ministry-province-year level data:

$$
y_{m p t}=\alpha \cdot \text { Connection }_{m p t}+X_{p t}^{\prime} \cdot \beta+\delta_{m p}+\theta_{t}+\varepsilon_{m p t},
$$

where $y_{m p t}$ is the number of experiments assigned to province $p$ by ministry $m$ in year $t$; Connection $n_{m p}$ is a dummy variable indicating whether the minister of ministry $m$ in year $t$ used to work full-time in province $p ; X_{p t}^{\prime}$ is a vector of provincial time-variant controls; and $\theta_{t}$ is year fixed effects. Importantly, we include $\delta_{m p}$, province-by-ministry fixed effects, which isolate the changes in a locality's connection to a particular ministry driven by minister turnovers.

As shown in Table $\Omega$, Panel A, when a region becomes connected to a minister, the number of experiments assigned to that region increases immediately by $28.8 \%$. ${ }^{\square}$ The effects are almost entirely driven by cases where the central ministry directly assigns the experimentation sites, while there is no comparable effect when the experimentation sites are selected via voluntary participation (see Appendix Table A.6). This suggests that the political patronage in experimentation site selection works through top-down favoritism.

Objectives beyond representative sample selection The patterns on career incentives and political patronage suggest that, even in the case that the central government's only objective is to obtain a representative sample of experimentation sites, deviation from representativeness in site selection could still occur in the implementation of policy experiments: principle-agent problems generate misaligned incentives between the central and local governments, and between the central government and its ministers.

In addition to achieving representativeness, the central government might have other

12. In Appendix Figure A.16, we plot the event study estimates around ministers' turnover. The absence of a pre-trend suggests that being connected to a ministry due to turnover of a central minister is indeed likely to be orthogonal to the counterfactual trajectories of local governments' experimentation behaviors. 
criteria when choosing experimentation sites, and these additional criteria may at times counteract its desire for representativeness. A particular example of such criteria concerns the central government's often overt and overarching objective of maintaining political stability during socioeconomic reforms. Specifically, we examine whether social and political unrest in a particular prefecture affects its chance of being selected as an experimentation site. We find a robust pattern, exploiting within-region, across-time variations in occurrences of unrest, showing that prefectures that have experienced social and political unrest in the preceding period are significantly and substantially less likely to become experimentation sites (see Table $\mathbf{Z}$, Panel C). This suggests that unstable local environment could be a veto condition that precludes participation in policy experimentation. The negative relationship between unrest and selection is much stronger in the case of top-down assignment to experimentation than in the case of voluntary participation (see Appendix Table A.7). This suggests that concerns about avoiding politically unstable localities are primarily held by the central government, rather than by potential local participants.

Accounting for observed positive selection Overall, the factors associated with misalignment across the political hierarchy could account for nearly $50 \%$ of the positive selection in experimentation sites that we observe. We provide several quantitative assessments of these factors in contributing to site selection in Appendix E.

\section{Do experiments induce strategic efforts?}

An important component of policy effectiveness is an incentive scheme that encourages sufficient effort from the local governments when they implement the policy. A policy experiment - perhaps due to its high visibility, high political reward, and explicit monitoring by the central government - may induce additional efforts by the local governments who are especially incentivized to make the policy at trial appear successful at its experimentation stage. While participation in successful experiments is associated with a substantial increase in local politicians' promotion, this is not the case for participation in failed experiments (see Appendix Table A.3).

In this section, we examine two particular aspects of deviation from representative experimental situation: local governments' allocation of fiscal resources (Section 5.J) and their efforts to differentiate during the implementation of experiments (Section 5.2). 


\subsection{Allocation of fiscal resources during experimentation}

Local fiscal expenditure is an important input in policy outcomes, and is strongly associated with overall local economic performance (see Appendix Table A.8). Do the local governments participating in policy experimentation significantly increase fiscal expenditure that may improve the outcome of the experiment?

To answer this question, we first match each policy experiment to one of the six broad fiscal expenditure domains that are consistently reported in the county fiscal expenditure data throughout our sample period: general administrative cost, infrastructure, economic production, agriculture/forestry/fishing, science/culture/education/health, and other. We then use a triple-differences strategy to examine whether the start of policy experimentation is associated with increases in fiscal expenditure in the corresponding domain. Specifically, we estimate the following econometric model using county-domainyear level data:

$$
y_{i k t}=\alpha \cdot \operatorname{Exp}_{i k t}+\lambda_{i t}+\delta_{k t}+\theta_{i k}+\varepsilon_{i k t}
$$

where $y_{i k t}$ is the ratio of fiscal domain $k$ specific to the experiment in the total fiscal expenditure in county $i$ during year $t$; Exp $i k t$ is the number of experiments in fiscal domain $k$ that county $i$ engaged in during year $t ; \lambda_{i t}, \delta_{k t}$, and $\delta_{k t}$ stand for county-by-year, domainby-year, and county-by-domain fixed effects, respectively.

The results are presented in Table B, Panel A. We observe a substantial increase in domain-specific fiscal expenditure (columns 1-3): an additional experiment increases the local expenditure in the corresponding category by about $2 \%$ in terms of share of total fiscal expenditure, and by more than $5 \%$ in terms of the level of expenditure. The increase in domain-specific fiscal expenditure during experimentation is greater if the local politicians face stronger career incentives at the time of the experiment (columns 4-6), consistent with the pattern that politically incentivized local leaders are particularly keen on making sure the policy experiments succeed in their regions of jurisdiction.

Importantly, the over-expenditure during the experimentation may not be sustained when a policy becomes national. Indeed, we do not find fiscal expenditure increases in specific domains among non-experimentation sites when the policy rolls out to the entire country, and this is the case regardless of career incentives of the local politicians at nonexperimentation sites (see Table B, Panel B). ${ }^{\text {[3] }}$

13. This finding echoes similar results that document short-term "window dressing" incentives among local politicians when their actions are more visible to the central government (e.g., Fang, Liu, and Zhou 2(201). 


\subsection{Political incentives and differentiation during experimentation}

Next, we examine whether local politicians with stronger career incentives differentiate their experimentation details more during policy implementation. Differentiation can signal effort and earn political credit as a "model experimentation site."

In order to capture local politicians' differentiation, we measure the extent to which local politicians issue policy experimentation documents that are distinct from the ones issued by other politicians participating in the same experiment. Specifically, we construct pairwise text similarity among documents issued by local governments on the corresponding policy experiment, calculated using Latent Similarity Analysis (LSA). This exercise follows Bertrand et al. (2020) and Acemoglu, Yang, and Zhou (2021) in spirit, and we describe details of the procedure in Appendix F.

After constructing pairwise text similarity across documents issued by the local governments for a specific experiment $p$, we measure each local government $i$ 's similarity with its peers that have participated in the same experiment in a previous wave, using the maximum similarity score among these pairs $\left(y_{i p}\right)$. We estimate the following econometric model:

$$
y_{i p}=\alpha \cdot \text { Incentive }_{i p}+\beta X_{i p}^{\prime}+\lambda_{i}+\delta_{p}+\gamma_{t}+\varepsilon_{i p},
$$

where Incentive $e_{i p}$ is the politicians' career incentives as in Section 4.4; $X_{i p}^{\prime}$ is a set of controls for the politicians (educational attainment and career experience in the central government); $\lambda_{i}$ is a full set of location fixed effects; $\delta_{p}$ is a full set of policy experiment fixed effects; and $\gamma_{t}$ is a full set of year fixed effects. Similarly to the exercise in Section 4.4, we exploit variations in politicians' career incentives due to the timing of the experiments and their age relative to retirement.

The results are presented in Table ta. We observe that, when local politicians have strong career incentives, they tend to differentiate more relative to their colleagues in terms of implementation details. While we cannot conclude whether such differentiation is sub-optimal (e.g., if policy solutions that are proven effective had already been tried out by their peers in previous waves of experimentation), the increase in policy implementation differentiation reflects an increase in local politicians' efforts in implementing the policy on trial. 


\section{What are the consequences on policy learning and policy outcomes?}

Having demonstrated that the sample selection bias and unrepresentative experimental situation are relevant in China's policy experimentation, we next examine the consequences of their presence. To the extent that the central government may not fully take into account the sample selection of experimentation sites, and the endogenous efforts local politicians exert that may not be sustainable after the experimentation stage, then policy learning could become biased - we investigate in the policy learning consequences in Section 6.1. To the extent that the central government's policy learning may be biased, this may shape the national policy outcomes in China - we investigate in the consequences on policy outcomes in Section 6.2.

\subsection{Central government's policy learning}

Policy learning and locality-specific shocks When evaluating experimentation outcomes, does the central government exclude locality-specific shocks that are orthogonal to the underlying policy effectiveness? In particular, does a local fiscal windfall during experimentation, which may improve local outcomes but unrelated to the innate effectiveness of the policy at trial, increase the likelihood that the central government evaluate the policy at trial to be successful?

We focus on land revenue (i.e., land conveyance fees) received by the county governments for converting agricultural land for non-agricultural use. This has been one of the most important sources of local fiscal revenue windfall in the 2000s (e.g., Han and Kung 2015). Following the empirical strategy of Chen and Kung (2016), we isolate the exogenous component of such land revenue windfall as a result of the interaction of two factors: (i) the amount of land in a county suitable for commercial and real estate development as determined by terrain; and (ii) exogenous time-varying demand shock driven by interest rates. We evaluate whether the land revenue increase due to these factors unrelated to policy experimentation and policy effectiveness per se may affect the chance that a policy experiment becomes successful and gets rolled out to the entire country.

Using a sample of all experimentation sites for each policy experiment, we estimate the following two-stage-least-squared specification:

$$
\begin{aligned}
\text { Land_revenue }_{i p t} & =\alpha \cdot \text { Suitability }_{i} \times \text { Interest }_{t}+X_{i t}^{\prime} \beta+\delta_{i}+\gamma_{t}+\delta_{m}+\epsilon_{i p t} \\
y_{p} & =\mu \cdot \text { Land_revenue }_{i p t}+X_{i t}^{\prime} \Gamma+\psi_{i}+v_{t}+\delta_{m}+\varepsilon_{i p m t}
\end{aligned}
$$


where Land_revenue $i p t$ is the log level of land conversion revenue obtained by county $i$, served as an experimentation site for policy $p$, in year $t$ during the experimentation. The instrumental variable is the interaction term between the geographic constraint on experimentation site $i$ 's land supply (determined by its land slope) with the temporal variations in the national interest rate in year $t . y_{p}$ is the indicator of whether policy $p$ eventually was rolled out to the entire country; $\psi_{i}$ is a full set of county fixed effects; $\delta_{m}$ is a full set of ministry fixed effects, and $v_{t}$ is a full set of time fixed effects. ${ }^{\text {[4] }}$

Consistent with Chen and Kung (2016), we find that the interaction between the land suitability index and temporal interest rate strongly and positively predicts the land revenue received by the local government in a specific year (see Appendix Table A.9 for the first stage results). Table 5 , Panel A presents the second stage results. We find robust positive coefficients of instrumented land revenue at experimentation sites on the corresponding policy's national roll-out. The estimates imply that, if an experimentationparticipating county's land revenue doubles in a given year due to an exogenous windfall, the policy at trial will be 2.9 percentage points more likely to eventually roll out to the entire country.

In other words, when policy experimentation is conducted in localities experiencing temporal shocks that could improve the policy outcome, the central government does not fully discount these factors, but instead mistakenly attributes them (at least partially) to the underlying policy effectiveness, resulting in biased policy learning and policy choices.

Policy learning and politician-specific shocks When evaluating experimentation outcomes, does the central government exclude politician-specific shocks that are orthogonal to the underlying policy effectiveness? In particular, we examine whether an increase in local politicians' career incentives (and thus increased effort as shown in Section 5) due to political turnover affects the central government's policy learning and increases the likelihood that the policy at trial be evaluated as successful.

We focus on local politicians' turnover taking place after the beginning of policy experimentation in the local region, and we distinguish whether the turnover leads to an increase or decrease in local politicians' career incentives as measured in Section 5.2. This allows us to isolate changes in local politicians' career incentives that are unrelated to either the underlying effectiveness of the policy at trial, or the local government's initial participation in the experiment.

14. Following Chen and Kung (2016), we also control for characteristics at the county level (log population and local GDP growth rate), at politician level (their age, educational attainment, whether they are a member of the Youth League, previous prefectural government experience, birth-county connection with the prefectural leader, and current year in office). 
Specifically, we estimate the following econometric model:

$$
y_{p}=\alpha \cdot \text { Turnover }_{i p}+\beta \cdot \text { Turnover }_{i p} \times \Delta \text { Incentive }_{i p}+\gamma_{t}+\delta_{m}+\theta_{n}+\varepsilon_{\text {ipmnt }},
$$

where $y_{p}$ is the indicator of experiment $p$ being evaluated as successful and rolling out to the entire country; Turnover $r_{i p}$ is the indicator of a change in the party secretary of the prefecture $i$ during the experimentation period of policy $p ; \Delta$ Incentive $_{i p}$ is the difference in career incentives between the incumbent at the beginning of the experiment and that of his or her immediate successor, following the calculation described in Appendix B.1; $\gamma_{t}$ is a full set of year fixed effects; $\delta_{m}$ is a full set of ministry fixed effects; and $\theta_{n}$ is a full set of province fixed effects.

Table 5, Panel B presents the results. We observe a consistent pattern that, for experiments that are implemented in localities that experienced more local political turnover after the start of the experiment, the corresponding policy at trial is substantially more likely to be evaluated as successful and become national policy. This is especially the case if the local political turnover results in an increase in local politicians' career incentives relative to the outgoing politicians. According to our estimates, if an experimentationparticipating prefecture experiences a political rotation that increases the local politician's career incentive by 1 standard deviation, then the probability that the policy at trial eventually rolls out to the whole country would increase by 7.1 percentage points. This suggests that, when policy experiments are conducted in localities that experience politicianrelated shocks that could improve the policy outcome, the central government attributes the outcome at least partially to policy effectiveness, again resulting in biases in policy learning. We do not observe similar effects with the rotation of politicians that preceded the policy experiments, suggesting that there is no generic pattern on increased roll-out associated with political rotation per se (see Appendix Table A.10).

Positively selected experimentation and national roll-out Finally, we document that policy experiments closer to being representative in their implementation are less likely to roll out to become nationwide policies. Appendix Table A.11 presents results where we predict the likelihood of policy roll-out based on the underlying t-statistics from the representativeness tests of the corresponding experiment's site selection. We observe a robust pattern that deviations from representativeness are associated with higher chances of rolling out to the entire country. Intriguingly, this association is much stronger among experiments that are ex-ante uncertain. While only suggestive, these results are consistent with the interpretation that the central government does not fully take into account the fact that positively selected experiments are less likely to reveal sub-optimal policies. 


\subsection{National policy outcomes}

Information loss due to unrepresentative sample Experimentation reflects the central government's desire to learn about the mapping from policy to outcome. A large degree of heterogeneity in the mapping from policy to outcome would imply a certain degree of information loss due to deviation from representativeness.

We illustrate such information loss using the context of a specific policy experiment on local fiscal empowerment. In order to foster economic growth across Chinese counties, the central government initiated an experiment that allows provincial governments to bypass prefectural governments and directly administer the counties within their jurisdiction, effectively providing fiscal empowerment to the counties participating in the experiment. Between 2003 and 2013, more than 1,100 counties were selected as experimentation sites (see Appendix A.2 for details).

We observe that the experimentation sites were positively selected during the first half of experiment ( $t$-stats of a $t$-test on pre-experimentation GDP per capita between experimentation and non-experimentation counties are as high as 9.110 during the first two years of experimentation), then shifted toward negative selection (t-stats decrease to -6.156 by 2007) and moved closer to representative selection toward the end of the experiment (see Appendix Figure A.17).

We find considerable heterogeneity in the effects of such experimentation on local economic development. Using a staggered event study design to estimate the treatment effects on local economic performance among experimentation counties in the early rounds (positively selected) and the later rounds (negatively selected), while controlling for county and year fixed effects, counties that have higher pre-experimentation GDP per capita benefited from the experiment, while the poorer counties experienced worse subsequent local economic development (see Appendix Figure A.18). ${ }^{\text {[5 }}$

In fact, the fiscal empowerment experiment, had it been rolled out to the entire country, would generate a net zero effect with both winners and losers (see Appendix Figure A.20 for the distribution of the projected treatment effects of the local fiscal empowerment for each county in China). This case of the local fiscal empowerment experiment demonstrates that unrepresentativeness of experimentation sites disproportionately highlights the positive effects of the policy, which could mask the unequal nature of the policy and in turn bias the central government's policy choices.

15. Such patterns of heterogeneity by pre-experimentation local economic conditions do not merely reflect a general equilibrium effect or an early-mover advantage of the local fiscal empowerment scheme. Lessdeveloped counties participating in the experiment during the early rounds also experienced a negative policy treatment effect in magnitudes similar to the less-developed experimentation sites in later rounds (see Appendix Figure A.19). 
Consequences due to positive selection of experimentation sites We next examine the overall effects of national policies originating from non-representative experimentation. When such policies roll out to the entire country, do localities similar to experimentation sites benefit more from the new policy?

For each experiment that eventually leads to national policies, we calculate the Mahalanobis distance between localities that participated in the experiment and those that did $\operatorname{not}\left(M_{c p}\right)$. The distance is calculated based on a vector of pre-experimentation local conditions: local GDP per capita, local fiscal income, and fiscal expenditure. We then examine, among localities that did not participate in the experimentation, whether a national policy leads to faster local economic growth when a specific county is socioeconomically similar to the experimentation sites of that corresponding policy. We estimate the following specification:

$$
\text { Growth }_{c p t}=\alpha \cdot M_{c p}+\gamma_{c}+\sigma_{t}+\eta_{p}+\epsilon_{c p t},
$$

where Growth $h_{c p}$ is (non-experimentation) county c's GDP growth after policy $p$ rolls out to the entire country, $\gamma_{c}$ is a full set of county fixed effects, $\sigma_{t}$ is a full set of year fixed effects, and $\eta_{p}$ is a full set of policy fixed effects.

The results are presented in Table G, Panel A. We observe that localities that did not participate in an experiment but are socioeconomically similar to the experimentation sites benefit significantly more from the policies when they roll out to the rest of the country. This result is robust to different indices chosen to compute the distance (See Appendix Table A.12).

These results suggest that policies originating from unrepresentative experiments differentially benefit some regions over others depending on the sample composition of the experimentation sites. Given that the experimentation sites are overwhelmingly positively selected in terms of local socioeconomic conditions, this would generate distributional consequences: positive selection of sites may produce a portfolio of policies that systematically favor the more developed regions at the expense of their less-developed counterparts, thus leading to greater inter-regional inequality throughout China.

Consequences due to endogenous efforts during experimentation Moving to factors related to endogenous efforts, we next investigate the effects of national policies originating from experiments that were implemented by local politicians with strong career incentives: when these policies roll out to the entire country, do local governments whose officials have levels of career incentives similar to the experimentation sites benefit more from the new policy?

We follow an empirical approach similar to the previous sub-section: for policy exper- 
iments that eventually lead to national policies, we calculate the Mahalanobis distance on the local government career incentives between localities that participated in the experiment (when the experiments started) and those that did not (when the policies rolled out to the entire country). We then estimate, among localities that did not participate in the experiment, whether national policies lead to faster local economic growth when a specific county is similar to the experimentation sites of the corresponding policy in terms of local government career incentives.

The results are presented in Table 6, Panel B. We find that non-experimentation sites with local politicians facing similar career incentives as the experimentation sites are better off when trial policies roll out to the entire country. This suggests that experimentation may structurally allow for better tailoring of policies to benefit from greater politician efforts. Note that, while we use identical measures of politicians' career incentives (as described in Appendix B.1) during and after the experiments, such career incentives could be associated with a greater degrees of effort during a trial (when local efforts are showcased) than during national implementation.

Adjusting for policy effects from experimentation To gauge the overall magnitude of policy experimentation's exaggerated signals and to guide adjustment on future policy learning, we estimate a "deflating coefficient" that maps policy effects observed during experimentation to effects among non-experimentation sites during national roll-out. Specifically, we first estimate the unconditional correlation between average effects of experimentation on local economic growth across experimentation sites and the average effects on non-experimentation sites when the corresponding policy rolls out to the entire country. Figure 4 presents the coefficient estimates. We find an unconditional deflating coefficient of $74 \%$, namely, the policy effects (on local economic growth) decrease by $74 \%$ once they roll out beyond the experimentation stage. This could capture both unobservable differences of policy implementations during and out of experimentation, as well as observable differences in experimentation sites' sample selection and endogenous efforts during the experimentation. When we take into account the sample selection and career incentives of local politicians during experimentation, the deflating coefficient further increases to $85 \%$, suggesting that the central government could improve the inference adjustment with these observable characteristics.

Complementarity between positive selection and endogenous efforts Career incentives of local politicians play an important role in explaining the positive selection of experimentation sites (as we have shown in Section 4.4); such career incentives also induce 
greater exertion of effort during experimentation (as shown in Section 5). This implies that one cannot easily decompose the effects on national outcomes into positive site selection versus endogenous local efforts. ${ }^{\text {[6 }}$

Rather, there exists complementarity between positive selection and endogenous efforts. Richer localities participating in experiments are also more likely to have local politicians with higher career incentives and thus will exert greater efforts during an experiment. On the contrary, non-experimentation sites are more likely to be localities where socioeconomic development is less advanced, and local politicians face weaker career incentives. Therefore, the negative selection of the non-experimentation sites cannot be compensated by greater efforts exerted by local politicians. In fact, the negative selection would be compounded by the additional disadvantage of the lack of local political incentives during policy implementation.

\section{Conclusion}

In this project, we systematically examine China's policy experimentation over the past four decades, one of the largest undertakings of systematic policy learning in recent history. We present three sets of results. First, policy experimentation sites are substantially positively selected, and misaligned incentives across political hierarchies account for much of the observed positive selection. Second, experimental situation during policy experimentation is unrepresentative: local politicians exert strategic efforts and allocate more resources during experimentation that may exaggerate policy effectiveness. Third, the positive sample selection and unrepresentative experimental situation are not fully accounted for when the central government evaluates experimentation outcomes, which would bias policy learning and national policies originated from the experiments.

We highlight that policy learning and policy experimentation inevitably take place in complex environments with various constraints and distortions. The political and bureaucratic environment could affect the initiation of policy experimentation, its structure and implementation, and the bias in the information one may gather from an experiment. Our findings stand in contrast with theoretical work analyzing experimentation in federalist environments featuring voluntary local initiatives (Mukand and Rodrik 2005; Callander and Harstad 2015; Myerson 2015). ${ }^{\square}$ While misaligned incentives between the central and local governments generate sub-optimal learning, rather than the informational free-

16. In fact, allowing local political incentives to affect site selection may be an important mechanism through which the central government induces politicians' efforts during experimentation.

17. Cheng and $\mathrm{Li}(2019)$ notes, however, that the uncertainty related to citizens' inference on politicians' types could induce politicians to over-experiment even in a decentralized environment. 
riding and under-experimentation observed in federalist systems, political centralization in a context such as China, where local governments compete and differentiate in order to increase their chances of promotion, could induce over-experimentation.

Our examination of China's policy experiments suggests that, while experimentation can facilitate reform and prevent policy disasters, one needs to pay attention to the manner in which policy experiments are conducted, as more information does not necessarily result in better decision making. ${ }^{18}$ Our findings that policies originating from unrepresentative experimentation could disproportionately benefit richer regions demonstrate yet another manifestation of regulatory capture - by systematically biasing the information that decision makers gather during the policy learning process - in addition to pure regulatory capture (e.g., Stigler 1971), capture through corruption (e.g., Shleifer 1996), and capture through enforcement (e.g., Glaeser and Shleifer 2003), recent literature has documented more subtle forms of cognitive capture of regulators (e.g., Johnson and Kwak 2017) and capture through philanthropic giving and strategic advocacy (Bertrand et al. 2020). ${ }^{\mathbb{1}}$ Moreover, our findings point to a fundamental trade-off that the central government faces: structuring political incentives in order to stimulate politicians' effort to improve policy outcomes, while making sure that such incentives are not exaggerated during the experimentation phase, so that policy learning remains unbiased. Future work on mechanism design solutions that could improve the efficiency of policy learning could be of great policy relevance and importance.

18. It is important to note that our work does not address the overall benefits of experimentation (as opposed to implementing national policies without going through any experimentation). This is an important avenue for future work.

19. Our evidence of informational capture through politically connected government officials also relates to the growing body of work documenting the costs and distortions associated with political patronage, specifically in China's context (e.g., Fisman and Wang 2015; Fisman et al. 20120). 


\section{References}

Acemoglu, Daron, David Y Yang, and Jie Zhou. 2021. "Political Pressure and the Direction of Research: Evidence from Chinas Academia." Working paper.

Aghion, Philippe, Patrick Bolton, Christopher Harris, and Bruno Jullien. 1991. "Optimal learning by experimentation." The review of economic studies 58 (4): 621-654.

Allcott, Hunt. 2015. "Site selection bias in program evaluation." The Quarterly Journal of Economics 130 (3): 1117-1165.

Banerjee, Abhijit V, Sylvain Chassang, Sergio Montero, and Erik Snowberg. 2020. "A theory of experimenters: Robustness, randomization, and balance." American Economic Review 110 (4): 1206-30.

Bergquist, Lauren, Benjamin Faber, Thibault Fally, Matthias Hoelzlein, Edward Miguel, and Andres Rodriguez-Clare. 2019. "Scaling Agricultural Policy Interventions: Theory and Evidence from Uganda." Unpublished manuscript, University of California at berkeley.

Bertrand, Marianne, Matilde Bombardini, Raymond Fisman, Brad Hackinen, and Francesco Trebbi. 2020. Hall of Mirrors: Corporate Philanthropy and Strategic Advocacy. Technical report. Boston University-Department of Economics.

Cai, Hongbin, Daniel Treisman, et al. 2009. "Political decentralization and policy experimentation." Quarterly Journal of Political Science 4 (1): 35-58.

Callander, Steven. 2011. "Searching for good policies." American Political Science Review, 643-662.

Callander, Steven, and Bård Harstad. 2015. "Experimentation in federal systems." The Quarterly Journal of Economics 130 (2): 951-1002.

Cao, Yuanzheng, Yingyi Qian, and Barry R Weingast. 1999. "From federalism, Chinese style to privatization, Chinese style." Economics of Transition 7 (1): 103-131.

Chandler, Alfred Dupont. 1962. Strategy and structure: Chapters in the history of the industrial enterprise. Vol. 120. MIT press.

Chen, Ting, and JK-S Kung. 2016. "Do land revenue windfalls create a political resource curse? Evidence from China." Journal of Development Economics 123:86-106.

Cheng, Chen, and Christopher Li. 2019. "Laboratories of democracy: Policy experimentation under decentralization." American Economic Journal: Microeconomics 11 (3): 12554.

Davis, Jonathan M.V., Jonathan Guryan, Kelly Hallberg, and Jens Ludwig. 2017. "The Economics of Scale-up." NBER Working Paper.

DellaVigna, Stefano, and Woojin Kim. 2021. "Policy Diffusion and Polarization across U.S. States."

DellaVigna, Stefano, and Elizabeth Linos. 2020. Rcts to scale: Comprehensive evidence from two nudge units. Technical report. National Bureau of Economic Research.

Dewatripont, Mathias, and Gerard Roland. 1995. "The design of reform packages under uncertainty." The American Economic Review, 1207-1223. 
Fang, Hanming, Chang Liu, and Li-An Zhou. 2020. Window Dressing in the Public Sector: A Case Study of Chinas Compulsory Education Promotion Program. Technical report. National Bureau of Economic Research.

Fisman, Raymond, Jing Shi, Yongxiang Wang, and Weixing Wu. 2020. "Social ties and the selection of China's political elite." American Economic Review 110 (6): 1752-81.

Fisman, Raymond, and Yongxiang Wang. 2015. "The mortality cost of political connections." The Review of Economic Studies 82 (4): 1346-1382.

Gechter, Michael, and Rachael Meager. 2021. "Combining Experimental and Observational Studies in Meta-Analysis: A Mutual Debiasing Approach."

Glaeser, Edward L, and Andrei Shleifer. 2003. "The rise of the regulatory state." Journal of economic literature 41 (2): 401-425.

Han, Li, and James Kai-Sing Kung. 2015. "Fiscal incentives and policy choices of local governments: Evidence from China." Journal of Development Economics 116:89-104.

Hayek, Friedrich August. 1978. Law, legislation and liberty, volume 1: Rules and order. Vol. 1. University of Chicago Press.

Heilmann, Sebastian. 2008a. "From local experiments to national policy: the origins of China's distinctive policy process." The China Journal, no. 59, 1-30.

. 2008b. "Policy experimentation in Chinas economic rise." Studies in Comparative International Development 43 (1): 1-26.

Hirsch, Alexander V. 2016. "Experimentation and persuasion in political organizations." American Political Science Review 110 (01): 68-84.

Hjort, Jonas, Diana Moreira, Gautam Rao, and Juan Francisco Santini. 2019. How research affects policy: Experimental evidence from 2,150 brazilian municipalities. Technical report. National Bureau of Economic Research.

Huang, Xiulan. 2000. "On Policy Experimentations in the Reform and Open Up Process." Probe 3:66-69.

Johnson, Simon, and James Kwak. 2011. 13 bankers: The Wall Street takeover and the next financial meltdown. Vintage.

Mehmood, Sultan, Shaheen Naseer, and Daniel L Chen. 2021. Training Policymakers in Econometrics. Technical report. Working Paper.

Montinola, Gabriella, Yingyi Qian, and Barry R Weingast. 1995. "Federalism, Chinese style: the political basis for economic success in China." World politics, 50-81.

Mukand, Sharun W, and Dani Rodrik. 2005. "In search of the holy grail: policy convergence, experimentation, and economic performance." American Economic Review 95 (1): 374-383.

Myerson, Roger. 2015. “Local Agency Costs of Political Centralization." U. Chicago Working Paper.

Naughton, Barry. 1996. Growing out of the plan: Chinese economic reform, 1978-1993. Cambridge university press.

North, Douglass C, et al. 1990. Institutions, institutional change and economic performance. Cambridge university press. 
Qian, Yingyi. 2002. "How reform worked in China."

Qian, Yingyi, Gerard Roland, and Chenggang Xu. 2006. “Coordination and experimentation in M-form and U-form organizations." Journal of Political Economy 114 (2): 366402.

Rawski, Thomas G. 1995. "Implications of China's reform experience." China Q., 1150.

Rogger, Daniel, and Ravi Somani. 2018. Hierarchy and information. The World Bank.

Roland, Gerard. 2000. Transition and economics: Politics, markets, and firms. MIT press.

Sachs, Jeffrey D. 2006. The end of poverty: Economic possibilities for our time. Penguin.

Shipan, Charles R, and Craig Volden. 2006. “Bottom-up federalism: The diffusion of antismoking policies from US cities to states." American journal of political science 50 (4): 825-843.

Shleifer, Andrei. 1996. "Origins of bad policies: Control, corruption and confusion." Rivista di Politica Economica.

Snowberg, Erik, and Leeat Yariv. 2018. "Testing the waters: Behavior across subject pools." NBER Working Paper No 24781.

Stigler, George J. 1971. "The theory of economic regulation." The Bell journal of economics and management science, 3-21.

Al-Ubaydli, Omar, John A. List, and Dana Suskind. 2019. "The Science of Using Science: Towards an Understanding of the Threats to Scaling Experiments." NBER Working Paper.

Vivalt, Eva. 2020. "How much can we generalize from impact evaluations?" Journal of the European Economic Association 18 (6): 3045-3089.

Vivalt, Eva, and Aidan Coville. 2019. How do policymakers update?

Wang, Zhi, Qinghua Zhang, and Li-An Zhou. 2020. “Career incentives of city leaders and urban spatial expansion in China." Review of Economics and Statistics 102 (5): 897-911.

Williamson, Oliver E. 1975. "Markets and hierarchies: analysis and antitrust implications: a study in the economics of internal organization." University of Illinois at UrbanaChampaign's Academy for Entrepreneurial Leadership Historical Research Reference in Entrepreneurship.

Wu, Youxi. 1995. "Analysis of Policy Experiment Methods." Reform of Economic System 6.

Xie, Yinxi, and Yang Xie. 2017. "Machiavellian experimentation." Journal of Comparative Economics 45 (4): 685-711.

$\mathrm{Xu}$, Chenggang. 2011. "The fundamental institutions of China's reforms and development." Journal of economic literature 49 (4): 1076-1151.

Zhou, Wang. 2013. Study on China's Experimental Points. Tianjin People's Press. 


\section{Figures and tables}

Total \# of experimentation, by province

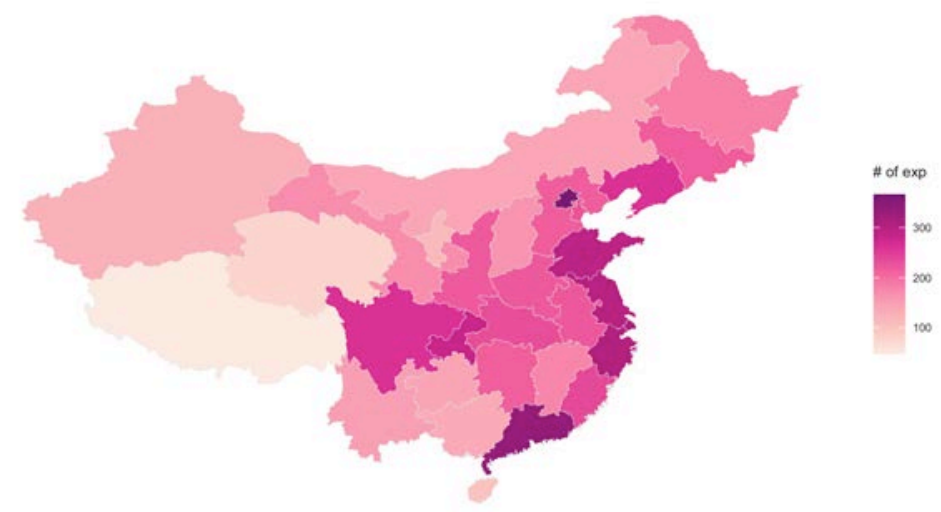

Panel A: Spatial distribution of policy experimentations
B.1 Carbon emission trading During 2011-2021

Experimentation in 1 wave

7 provinces / cities as experimentation sites

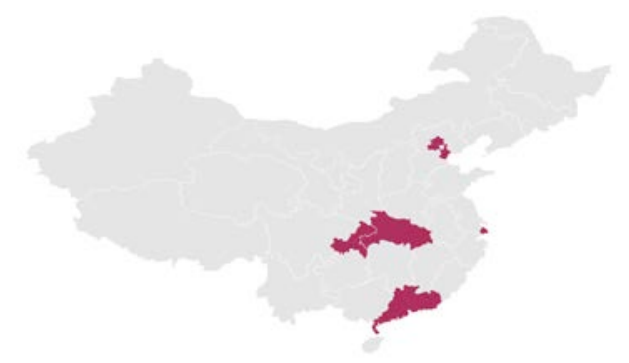

B.3 Agriculture catastrophe insurance During 2017-2021

Experimentation in 2 waves

14 provinces as experimentation sites

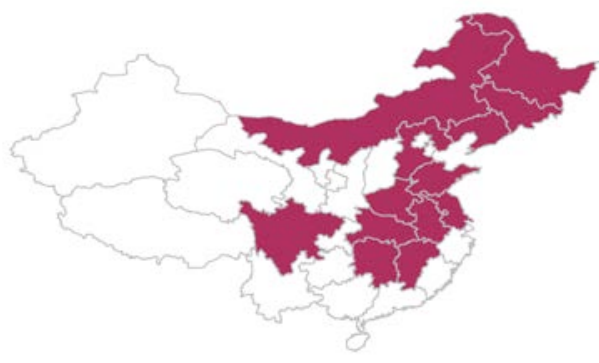

B.2 Separation of permits and licenses During 2015-2018

Experimentation in 3 waves

24 prefectures as experimentation sites

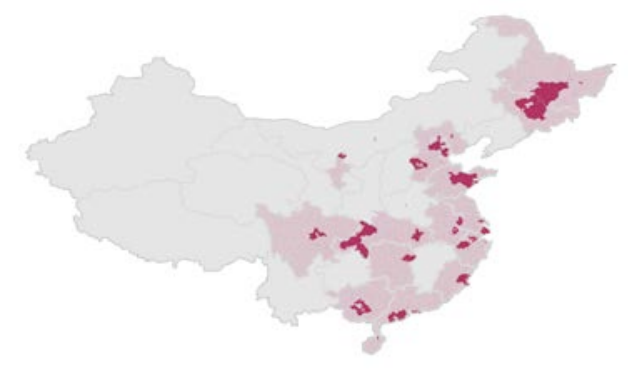

B.4 County fiscal empowerment reform During 2002-2015

Experimentation in $10+$ waves

1,246 counties as experimentation sites

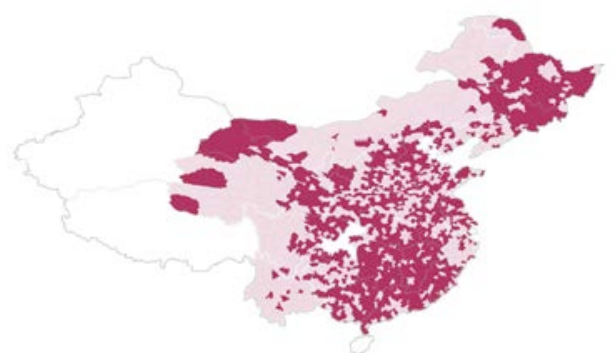

Panel B: Examples of policy experimentation

Figure 1: These maps plot the spatial distribution of policy experimentation in China. Panel A counts the total number of policy experiments that each province has been involved in (including experiments at prefectural and county levels). Panels B.1 and B.2 show two policies that eventually rolled out to the entire country. The regions shaded in grey indicate parts of the country that eventually received the policy. Panels B.3 and B.4 show two policies that did not eventually roll out. The experimentation sites are marked in red, and the corresponding provinces are marked in pink. 


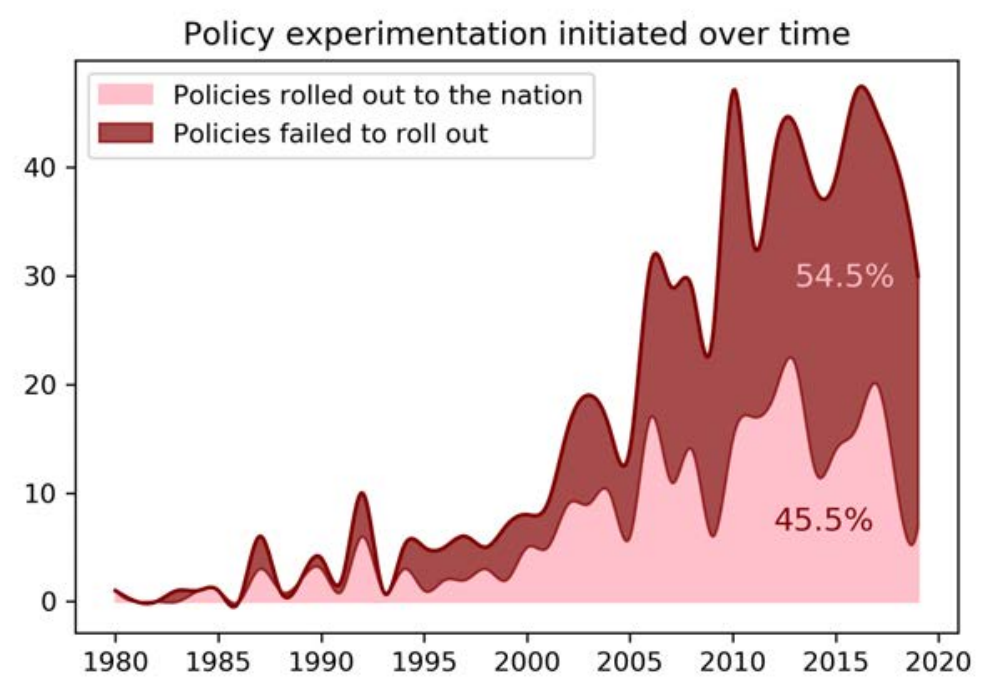

Figure 2: This figure plots the number of policy experiments initiated over time. The share of successful experiments that eventually rolled out to the entire country is indicated by the area shaded in pink; the share of unsuccessful policies that failed to roll out to the entire country is indicated by the area shaded in red.

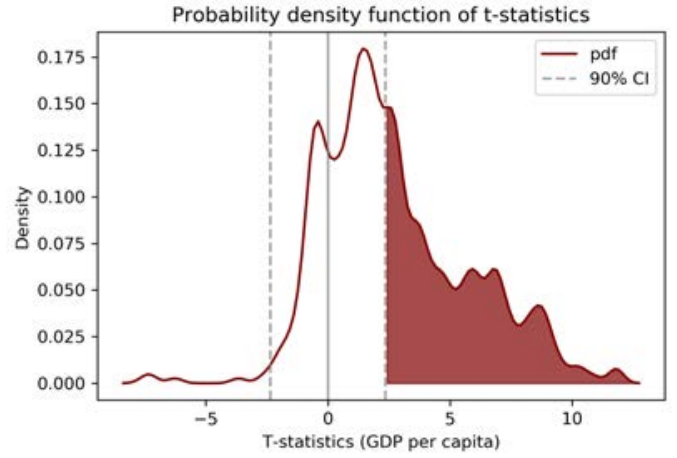

Panel A

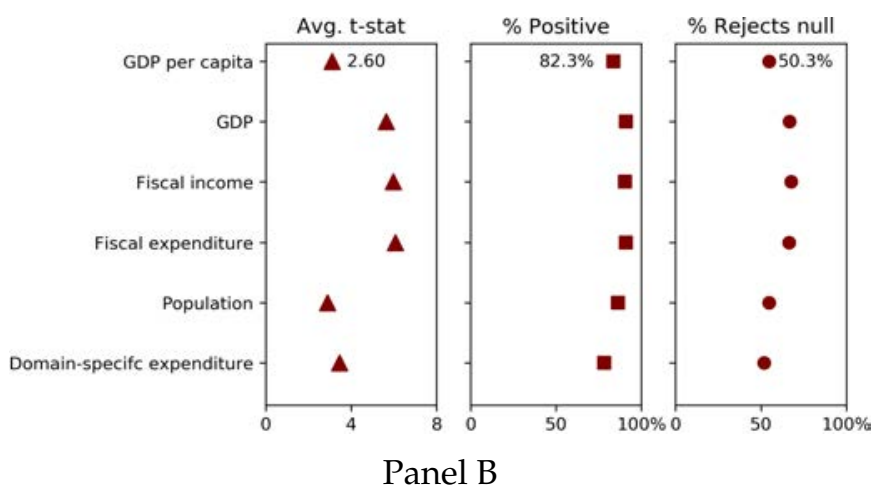

Panel B

Figure 3: This figure shows descriptive facts on the representative test. Panel A plots the $\mathrm{t}$-statistics distribution from the representativeness test, calculated based on GDP per capita, to serve as an example. Panel B extends the list to more socioeconomic characteristics, and reported the mean of t-statistics, the percentage of policies with $t$-stat $>0$, and the percentage of tests where we can reject the null hypothesis $H_{0}: \bar{Y}(0)=\bar{Y}(1)$ in three sub-panels, respectively. To calculate the t-statistics, we compare the average pre-experimentation characteristics between those jurisdictions chosen as experimentation sites, and their peers at the same hierarchical level that were not chosen as experimentation sites within each test. The grey vertical lines in panel A represent the average critical value at $90 \%$ confidence level among all $\mathrm{t}$-tests. 


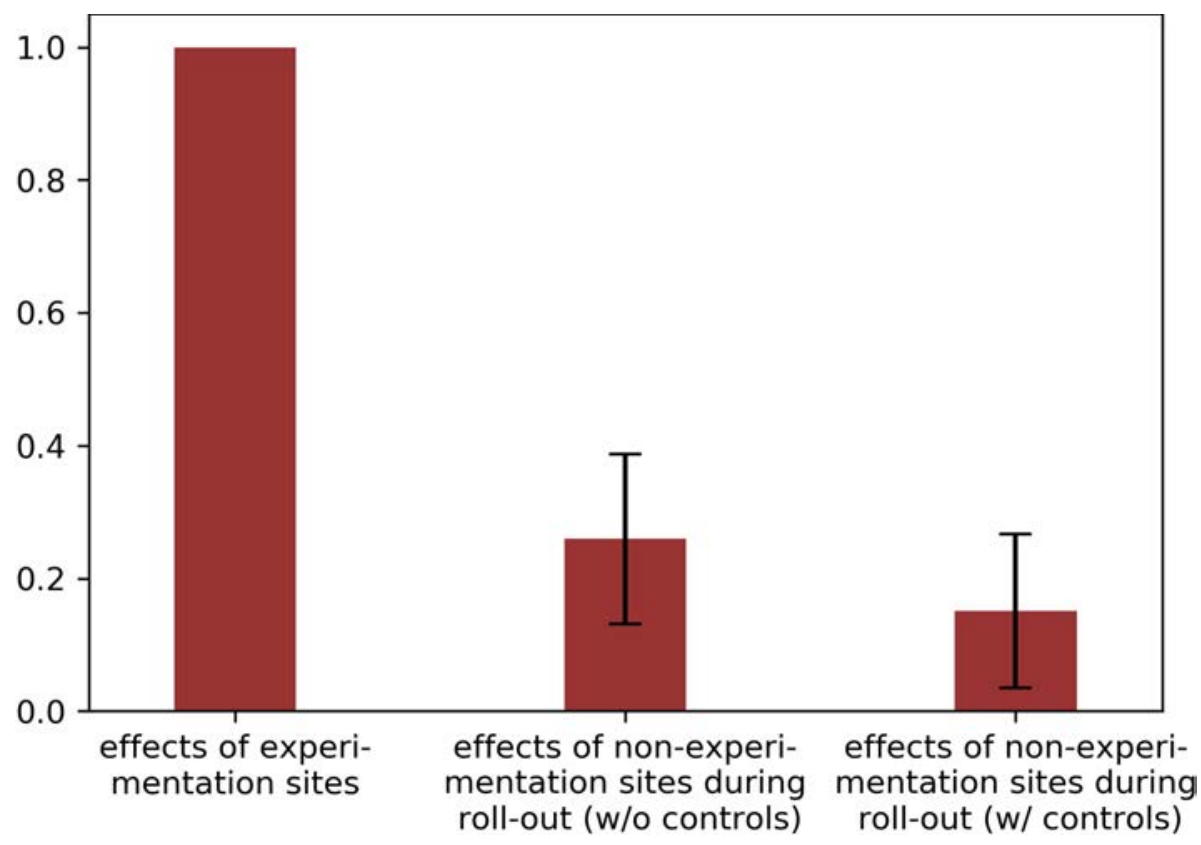

Figure 4: The figure shows the difference between the average treatment effects of experimentation sites (standardized to 1), and the average treatment effects of non-experimentation sites during policy roll-out. The whiskers illustrate the $95 \%$ confidence intervals of the point estimate for this deflator. Treatment effects are measured by the growth rate of GDP per capita, in logarithm terms. Standard errors are clustered at policy level. 
Table 1: Summary statistics of policy experimentation

\begin{tabular}{|c|c|c|c|c|c|c|}
\hline & $\begin{array}{l}\text { \# of } \\
\text { exp. }\end{array}$ & $\begin{array}{c}\text { \# of } \\
\text { rounds }\end{array}$ & $\begin{array}{l}\text { \# of } \\
\text { sites }\end{array}$ & $\begin{array}{c}\% \\
\text { roll-out }\end{array}$ & $\begin{array}{l}\text { Avg. } \\
\text { t-stats }\end{array}$ & $\begin{array}{l}\% \text { repre- } \\
\text { sentative }\end{array}$ \\
\hline & $(1)$ & $(2)$ & (3) & $(4)$ & (5) & (6) \\
\hline \multicolumn{7}{|l|}{ Panel A: Full sample } \\
\hline Overall & 633 & 2.9 & 19.1 & 44.7 & 2.60 & 49.7 \\
\hline National & 594 & 2.9 & 19.7 & 46.0 & 2.70 & 48.2 \\
\hline$\times$ Completed & 494 & 3.0 & 18.4 & 54.5 & 2.80 & 45.3 \\
\hline$\times$ Ongoing & 100 & 2.7 & 26.2 & 4.0 & 2.15 & 63.1 \\
\hline Subnational & 39 & 2.8 & 9.1 & 25.6 & 1.04 & 74.2 \\
\hline$\times$ Completed & 35 & 2.9 & 9.7 & 25.7 & 1.08 & 75.0 \\
\hline$\times$ Ongoing & 4 & 1.5 & 4.2 & 25.0 & 0.64 & 66.7 \\
\hline \multicolumn{7}{|l|}{ Panel B: By policy domain } \\
\hline Resource, energy \& environment & 80 & 2.5 & 12.1 & 40.0 & 2.20 & 63.2 \\
\hline Market supervision & 77 & 2.5 & 11.4 & 49.4 & 3.22 & 32.8 \\
\hline Agriculture & 57 & 3.4 & 32.9 & 31.6 & 1.89 & 62.5 \\
\hline Education & 54 & 3.1 & 43.0 & 48.1 & 2.75 & 34.0 \\
\hline Finance & 53 & 2.5 & 6.3 & 49.1 & 5.27 & 36.4 \\
\hline Tax \& fiscal policy & 41 & 3.3 & 10.7 & 53.7 & 2.85 & 55.9 \\
\hline Commerce \& trade & 36 & 4.3 & 17.9 & 41.7 & 3.70 & 20.7 \\
\hline Population \& health & 35 & 3.1 & 22.9 & 48.6 & 2.07 & 41.2 \\
\hline Domestic affairs & 31 & 2.8 & 16.6 & 32.3 & 1.72 & 57.7 \\
\hline Development \& reform & 28 & 3.2 & 25.5 & 39.3 & 2.13 & 55.0 \\
\hline Industry \& information technology & 27 & 2.6 & 21.2 & 40.7 & 4.00 & 40.0 \\
\hline Labor \& personnel & 22 & 3.2 & 10.2 & 50.0 & 2.25 & 50.0 \\
\hline Transportation & 20 & 2.1 & 9.7 & 60.0 & 0.93 & 84.2 \\
\hline Others & 33 & 3.2 & 37.9 & 72.7 & 3.04 & 42.4 \\
\hline \multicolumn{7}{|l|}{ Panel C: By ex-ante certainty } \\
\hline Certain & 190 & 3.3 & 22.7 & 63.7 & 2.12 & 46.8 \\
\hline Uncertain & 404 & 2.8 & 18.3 & 37.6 & 2.95 & 48.7 \\
\hline \multicolumn{7}{|l|}{ Panel D: By complexity } \\
\hline Single-ministry & 451 & 2.2 & 14.3 & 42.6 & 2.65 & 52.1 \\
\hline Multi-ministry & 143 & 5.2 & 37.0 & 56.6 & 2.84 & 36.7 \\
\hline \multicolumn{7}{|l|}{ Panel E: By sign-up process } \\
\hline Opt-in & 270 & 3.2 & 30.6 & 45.9 & 3.01 & 36.3 \\
\hline Top-down & 324 & 2.8 & 11.8 & 45.7 & 2.53 & 61.4 \\
\hline \multicolumn{7}{|l|}{ Panel F: By administrative level } \\
\hline Province level & 198 & 1.4 & 4.8 & 36.9 & 1.11 & 72.1 \\
\hline City level & 260 & 3.1 & 10.6 & 59.6 & 4.30 & 28.9 \\
\hline County level & 136 & 4.9 & 58.9 & 33.1 & 1.55 & 57.0 \\
\hline
\end{tabular}


Table 2: Political incentives and policy experimentation

\begin{tabular}{|c|c|c|c|}
\hline & \multicolumn{3}{|c|}{ Engage in experimentation } \\
\hline & (1) & $(2)$ & (3) \\
\hline \multicolumn{4}{|c|}{ Panel A: Local politicians' career incentive } \\
\hline Career incentive & $\begin{array}{l}1.397^{*} \\
(0.796)\end{array}$ & $\begin{array}{l}1.405^{*} \\
(0.824)\end{array}$ & $\begin{array}{l}1.309 * \\
(0.791)\end{array}$ \\
\hline $\begin{array}{l}\text { \# of obs. } \\
\text { Mean of DV }\end{array}$ & $\begin{array}{l}7630 \\
1.059\end{array}$ & $\begin{array}{l}7630 \\
1.059\end{array}$ & $\begin{array}{r}7630 \\
1.059\end{array}$ \\
\hline $\begin{array}{l}\text { Prefecture controls } \\
\text { Politician controls } \\
\text { Year FE } \\
\text { Prefecture FE }\end{array}$ & $\begin{array}{l}\text { No } \\
\text { No } \\
\text { Yes } \\
\text { Yes }\end{array}$ & $\begin{array}{l}\text { No } \\
\text { Yes } \\
\text { Yes } \\
\text { Yes }\end{array}$ & $\begin{array}{l}\text { Yes } \\
\text { Yes } \\
\text { Yes } \\
\text { Yes }\end{array}$ \\
\hline \multicolumn{4}{|l|}{ Panel B: Political patronage } \\
\hline Connected to minister & $\begin{array}{l}0.088^{* *} \\
(0.035)\end{array}$ & $\begin{array}{l}0.062^{*} \\
(0.036)\end{array}$ & $\begin{array}{c}0.063^{*} \\
(0.037)\end{array}$ \\
\hline $\begin{array}{l}\text { \# of obs. } \\
\text { Mean of DV }\end{array}$ & $\begin{array}{l}42884 \\
0.214\end{array}$ & $\begin{array}{l}42884 \\
0.214\end{array}$ & $\begin{array}{l}42884 \\
0.214\end{array}$ \\
\hline $\begin{array}{l}\text { Controls } \\
\text { Year FE } \\
\text { Ministry by province FE }\end{array}$ & $\begin{array}{l}\text { No } \\
\text { No } \\
\text { Yes }\end{array}$ & $\begin{array}{l}\text { No } \\
\text { Yes } \\
\text { Yes }\end{array}$ & $\begin{array}{l}\text { Yes } \\
\text { Yes } \\
\text { Yes }\end{array}$ \\
\hline \multicolumn{4}{|c|}{ Panel C: Political stability concerns } \\
\hline \# of protests in previous year & $\begin{array}{l}-0.004^{* *} \\
(0.002)\end{array}$ & $\begin{array}{c}-0.002^{* *} \\
(0.001)\end{array}$ & $\begin{array}{l}-0.003^{* * *} \\
(0.0002)\end{array}$ \\
\hline $\begin{array}{l}\text { \# of obs. } \\
\text { Mean of DV }\end{array}$ & $\begin{array}{l}1519 \\
1.135\end{array}$ & $\begin{array}{l}1519 \\
1.135\end{array}$ & $\begin{array}{c}757 \\
2.043\end{array}$ \\
\hline $\begin{array}{l}\text { Pre-period controls } \\
\text { Year FE } \\
\text { Prefecture FE }\end{array}$ & $\begin{array}{l}\text { No } \\
\text { No } \\
\text { Yes }\end{array}$ & $\begin{array}{l}\text { No } \\
\text { Yes } \\
\text { Yes }\end{array}$ & $\begin{array}{l}\text { Yes } \\
\text { Yes } \\
\text { Yes }\end{array}$ \\
\hline
\end{tabular}

Note: In this table we investigate how various forms of political distortion affect policy experimentation. In panel A, Connection is the indicator of whether the current minister possesses any full-time previous work experience in a given province. Incentive, in panel $\mathrm{B}$, is the fitted probability of a prefectural party secretary's political promotion, as detailed in Appendix section B.1. Protest data is panel C is collected from Global Database of Events, Language, and Tone (GDELT). Standard errors are clustered at the province level in Panel A; and the prefecture level in Panels B and C. 
Table 3: Local fiscal expenditure during policy experimentation

Share of fiscal expenditure on experimentation-related domains

(1)

(2)

(3)

(4)

(5)

(6)

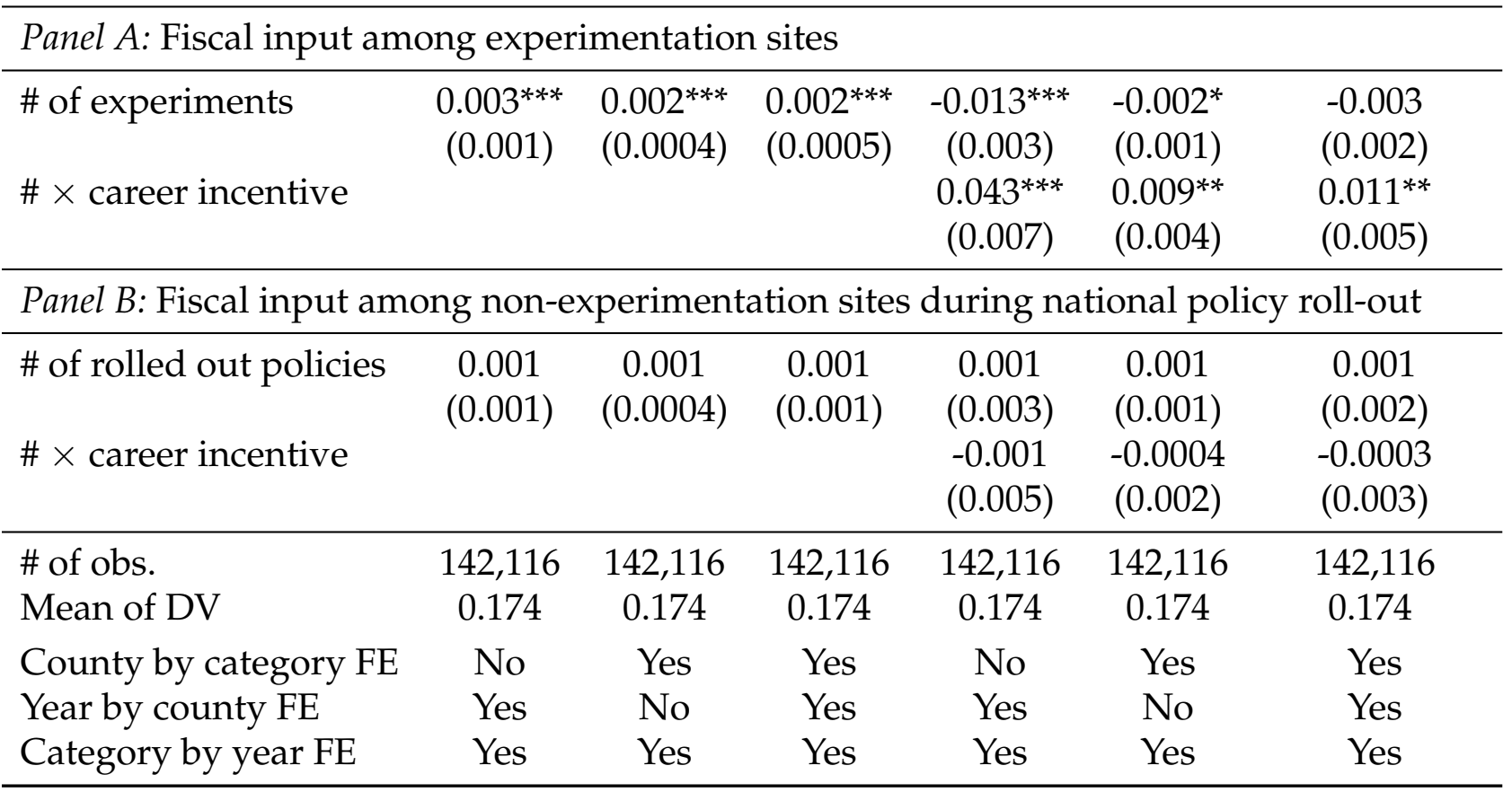

Note: This table estimates the impact of a policy experiment on the fiscal expenditures of its experimentation sites. We characterize six general fiscal domains, and match each policy experiment to its most closely related domain. In panel $\mathrm{A}$, we investigate whether the experimentation units re-allocated fiscal resources to the corresponding fiscal domain when a policy experiment is assigned. In panel B, we investigate whether the previously non-experimentation sites exhibited similar fiscal reallocation in the year that the policy rolled out nationally. Standard errors are clustered at county level. 
Table 4: Biased policy learning from experimentation

\begin{tabular}{lcccc}
\hline & \multicolumn{4}{c}{ Similarity index } \\
\cline { 2 - 5 } & $(1)$ & $(2)$ & $(3)$ & $(4)$ \\
\hline Career incentive & $-0.052^{* *}$ & $-0.066^{* *}$ & $-0.066^{* *}$ & $-0.076^{* *}$ \\
& $(0.027)$ & $(0.032)$ & $(0.033)$ & $(0.038)$ \\
\hline \# of obs. & 1,148 & 1,148 & 1,148 & 1,148 \\
Mean of DV & 0.980 & 0.980 & 0.980 & 0.980 \\
Politician Controls & No & No & No & Yes \\
Policy FE & Yes & Yes & Yes & Yes \\
Year FE & No & No & Yes & Yes \\
Prefecture FE & No & Yes & Yes & Yes \\
\hline
\end{tabular}

Note: In this table, we investigate how a politician's career incentive affects how his policy experimentation plan differs from that of his peers. Career incentive is measured by the fitted probability of a prefectural party secretary's political promotion, as detailed in Appendix section B.1. For the outcome variable, we conduct Latent Semantic Analysis, a canonical approach from Natural Language Processing, to measure the text similarity of government documents, which is detailed in Appendix Section F. The similarity index, taking maximum over all similarity pairs between a document and all others issued by its counterpart administrations on the same policy, aims at measuring how much a local government politician differentiates from his or her colleagues in the policy design during experimentation. We exclude all the documents from single-wave experiments and first wave documents from multi-wave experiments. We also restrict the sample to the first key document issued by each experimentation site in each wave, and drop the follow-up documents issued within the same site-wave unit. Politician controls include his or her level of education and previous central experience. Standard errors are clustered at policy level. 
Table 5: Irrational decomposition during experimentation evaluation

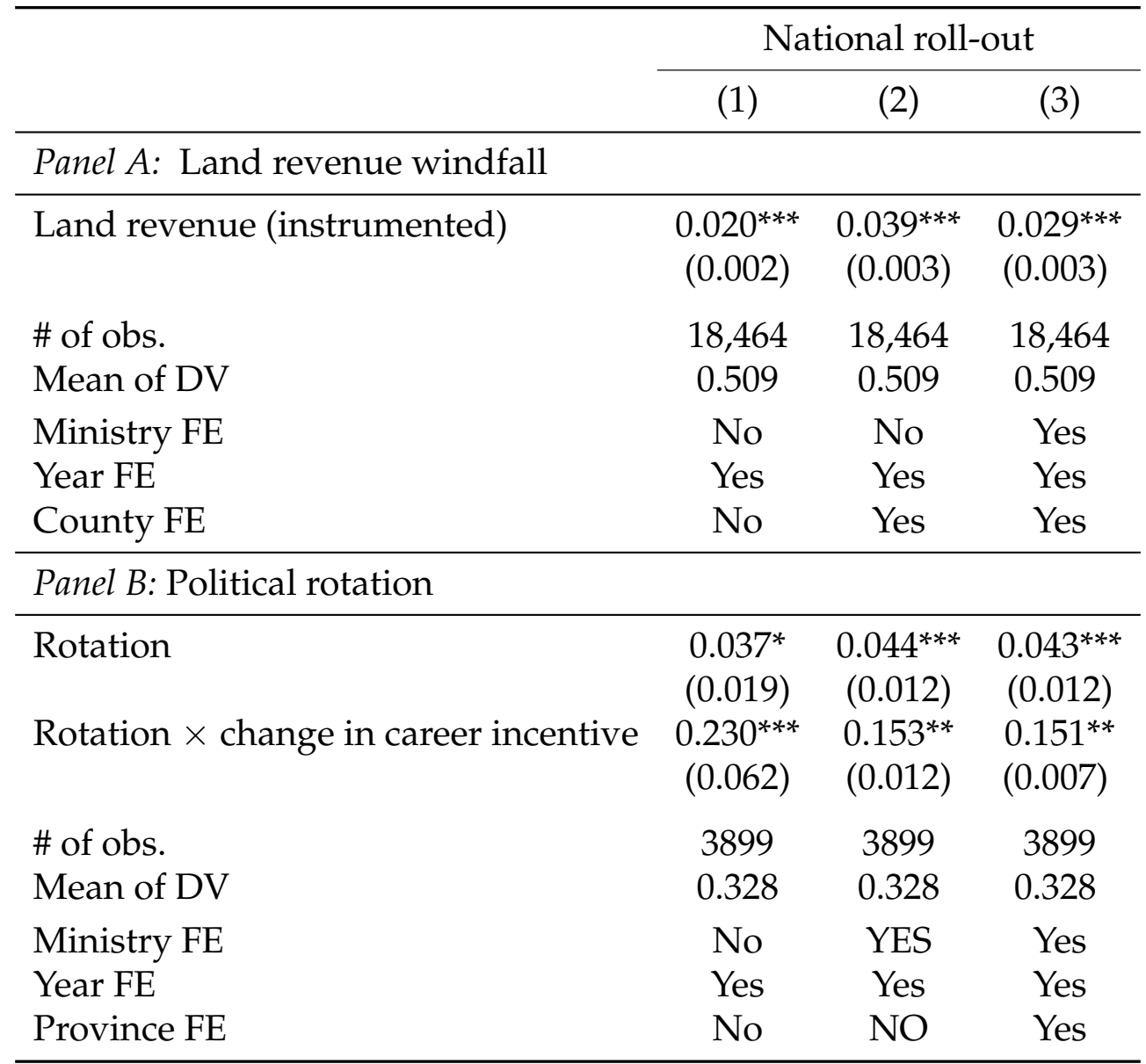

Note: In this table, we investigate whether external shocks to a policy experiment's sites and the local officials affect its likelihood of being rolled out. Panel A reports the second stage of a 2SLS regression where we use the interaction term between area of land unsuitable for agricultural use and national interest rate to instrument for the land revenue received by the local government. We report the first stage results in Appendix Table A.9. We include politician-level control variables including the mean of his or her age across the period, education, past experience in the prefectural government, previous positions as Youth League party leaders, and hometown-connection with the prefectural leaders. Panel B is an analysis focusing on political rotations that happened after the selection of experimentation sites. At the experiment-by-prefecture level, we calculate the difference in career incentives between the leaving prefectural official and his immediate successor. Rotation is a dummy variable indicating political turnover during the experimentation, which is defined to be the period between the start of the first round of experimentation and two years after the last round. The standard errors are clustered at the province level. 
Table 6: Similarity with experimentation sites and effects of policy roll-out

\begin{tabular}{lccc}
\hline & \multicolumn{3}{c}{ GDP per capita growth } \\
\cline { 2 - 4 } & $(1)$ & $(2)$ & $(3)$ \\
\hline Panel A: Selection of experimentation sites & & \\
\hline M-distance between local development & $-0.007^{* * *}$ & $-0.007^{* * *}$ & $-0.006^{* * *}$ \\
& $(0.001)$ & $(0.001)$ & $(0.001)$ \\
\# of obs. & 77,588 & 77,588 & 77,588 \\
Mean of DV & 0.0806 & 0.0806 & 0.0806 \\
\hline Panel B: Endogenous efforts during experimentation & \\
\hline M-distance between career incentives & $-0.001^{* * *}$ & $-0.002^{* * *}$ & -0.0001 \\
& $(0.0002)$ & $(0.0003)$ & $(0.0002)$ \\
\# of obs. & 86,221 & 86,221 & 86,221 \\
Mean of DV & 0.0930 & 0.0930 & 0.0930 \\
\hline Policy FE & No & No & Yes \\
Year FE & No & Yes & Yes \\
County FE & Yes & Yes & Yes \\
\hline
\end{tabular}

Note: This table investigates how much of a policy's (in)effectiveness at the national rollout stage can be attributed to the site selection and endogenous effort patterns at its experimentation stage. The sample includes all non-experimentation counties in years that a former policy experiment is being rolled out as a national policy. In Panel A, we look at the Mahalanobis distance between experimentation and non-experimentation counties for a given policy experiment, in terms of their socioeconomic conditions. In Panel B, we investigate Mahalanobis distance between the experimentation and non-experimentation sites in terms of political incentives, where career incentive is measured by the fitted probability of a prefectural party secretary's political promotion, as detailed in Appendix section B.1. The estimated covariance matrix in computing a Mahalanobis distance is fitted by the observed distribution of the data. Mahalanobis distances, in both panels, are standardized to mean zero and unit variance. Standard errors are clustered at county level. 